NBER WORKING PAPER SERIES

\title{
INCENTIVE-COMPATIBLE GUARANTEED \\ RENEWABLE HEALTH INSURANCE
}

\author{
Bradley Herring \\ Mark Pauly \\ Working Paper 9888 \\ http://www.nber.org/papers/w9888
}

\author{
NATIONAL BUREAU OF ECONOMIC RESEARCH \\ 1050 Massachusetts Avenue \\ Cambridge, MA 02138 \\ July 2003
}

This research was supported by a grant from the Robert Wood Johnson Foundation. We appreciate helpful comments from Keith Crocker, John Moran, Tom McGuire, seminar participants at both the 2003 NBER Insurance Project Meeting and the 2003 14th Annual Health Economics conference at RAND, and several health insurance actuaries participating in a focus group at the University of Pennsylvania in March, 2003. The views expressed herein are those of the authors and not necessarily those of the National Bureau of Economic Research.

(C2003 by Bradley Herring and Mark Pauly. All rights reserved. Short sections of text, not to exceed two paragraphs, may be quoted without explicit permission provided that full credit, including $(\subset$ notice, is given to the source. 
Incentive-Compatible Guaranteed Renewable Health Insurance

Bradley Herring and Mark Pauly

NBER Working Paper No. 9888

July 2003

JEL No.G22, I10

\begin{abstract}
Multi-period theoretical models of renewable insurance display front-loaded premium schedules that both cover lifetime total claims of low-risk and high-risk individuals and provide an incentive for those who remain low-risk to continue to purchase the policy. In practice, however, an age profile of premiums that decreases with age might result in relatively high premiums for younger individuals which they may consider unaffordable. In this paper, we use medical expenditure data to estimate an optimal competitive age-based premium schedule for a benchmark renewable health insurance policy. We find that the amount of prepayment by younger individuals that would be necessary to cover future claims is mitigated by three factors: high-risk individuals will either recover or die, low-risk expected expense increases with age, and the likelihood of developing a high-risk condition increases with age. Although medical cost growth over time increases the amount of prepayment necessary, the resulting optimal premium path generally increases with age.

We also find that actual premium paths exhibited by purchasers of individual insurance with guaranteed renewability is close to the optimal schedule we estimate. Finally, we examine consumers' gain in expected utility associated with the guaranteed renewability feature.
\end{abstract}

Bradley Herring

Department of Health Policy and Management

Rollins School of Public Health

Emory University

1518 Clifton Road NE

Atlanta, GA 30322

bjherri@sph.emory.edu
Mark Pauly

The Health Care Systems Department

The Wharton School

University of Pennsylvania

3641 Locust Walk

Philadelphia, PA 19104

and NBER

pauly@wharton.upenn.edu 


\section{INTRODUCTION}

\section{I.A. Background}

Not all illness-related events begin and end within the single-year time frame that is typical for private health insurance policies. This means that a person initially in good health who develops a chronic illness may have above-average expenses in subsequent years. If the annual insurance premium is set proportional to expected expense in each year, the person who contracts a multi-year condition would face a substantial and unexpected jump in premiums, something a risk-averse person would prefer to avoid. A potential solution to this problem is for the insurance policy purchased when the individual is still in good health to contain a guaranteed renewability (GR) provision which stipulates that no insured's future premium for the given policy will increase more than any other insured's premium increases. That is, people who become high-risk will pay the same premium as those who remain low-risk.

However, in a world of competitive unsubsidized insurance firms, the insurer faces a dilemma. If some individuals who are low-risk in period one will become high-risk in period two, any resulting second-period premium based only on these higher expected expenses may drive away from the plan those who remain low-risk. They will be attracted to other firms promising to charge them no more than their own expected expenses. In this sense, the promise to "community rate" insurance in the future for the population of initial purchasers is not sustainable in competitive insurance markets.

There is, however, a solution in theory to this problem, as suggested by Cochrane [1995] and Pauly, Kunreuther, and Hirth [1995]. The premium the insurer should charge the low-risk individuals in period one should be higher than the expected expense for that population in period one. The "extra" premium is used to cover the subsequent above-average expenses of 
those who became high-risk between period one and period two. It would then be possible to charge a premium equal to the low-risk individuals' expected expense in period two; at this premium, both those who became high-risk and those who remain low-risk would remain with the insurer. Moreover, risk-averse individuals will prefer paying the somewhat higher premium in period one to paying a lower premium in period one and facing the uncertainty of aboveaverage premiums in period two. The expected lifetime premiums are the same under both scenarios, but "front-loading" the first-period premium produces an "incentive-compatible" schedule of premiums which risk-averse individuals prefer to facing single-period risk-rated insurance.

In just a two-period model, the additional premium in period one need not be large. However, selling insurance to young people that will guarantee premiums in the face of a chronic illness that persists for many years into the future might require charging a substantial extra premium to cover the future expected excess expense for those who become high risk. Figure 1 illustrates what the theoretically-implied GR premium schedule would look like for a initially low-risk population in which individuals face a constant per-period probability of becoming (and remaining) high risk. Whereas a simple premium schedule based on age would obviously increase with age, the incentive-compatible guaranteed renewable premium schedule under this set of simple assumptions would decrease with age. Even with an insurer's ability to earn a rate of return on any reserves set aside for future claims, the additional premium to cover 40 or more years of above-average spending might be quite high. If people could borrow in a perfect capital market to pay this premium, they would do so. But, as Frick [1999] points out, with imperfect capital markets, young people - particularly those with lower incomes - might be unable to 
borrow on reasonable terms and therefore be unable to afford (even if behaving rationally in all other ways) high initial premiums.

However, this pattern of excessively high initial premiums may not be realistic for health insurance. The simple model assumed that the expected expenses for low-risk individuals stayed constant over time, that a given proportion of the low-risk population converted to high risk in every period, and that individuals remain high-risk for all remaining periods. These assumptions may well not hold for health insurance. Expected expenses even for healthy or normal people almost surely increase with age. Similarly, the probability of contracting a chronic condition also almost surely increases with age. And finally, the time period over which people remain high-risk, on average, is less than the average lifetime. (These conjectures are confirmed below with our medical expenditure data.)

The implication of these modifications is that, in principle, the premium needed to fund GR coverage might actually be moderate at a young age compared to what it will become later. In fact, premiums for guaranteed renewable coverage for people in their twenties (including enough to cover the excess expense of those who will become chronic high risks) could well be lower than the premiums for healthy people in their sixties, since the latter's expected expenses would be higher and more of them would be becoming high risks (if only until they go on Medicare). Applying a positive interest rate to the excess reserves collected by insurers would also smooth the life-long pattern of premiums.

At a theoretical level, this observation does not, in itself, necessarily provide a solution to Frick's problem of imperfect capital markets. Markets may be imperfect in many ways, and even with premiums that are relatively low for the young, those people may so prefer current consumption that they sacrifice GR protection. The real issue is empirical: what schedule of 
lifetime premiums related to age would individuals prefer? This paper does not answer that question directly. But it does estimate a feasible breakeven incentive-compatible premium schedule and approximates the willingness-to-pay for that schedule of lifetime premiums. We also relate these schedules to typical lifetime income patterns; in an informal way this comparison may suggest how "affordable" an incentive-compatible schedule would be.

There is another empirical fact that is relevant. GR health insurance policies (as well as GR term life and nursing home insurance) do exist in (and dominate) the market, even in the absence of regulation, and appear to be stable [Pauly, Percy, and Herring, 1999; Harrington and Niehaus, 1999]. We want to see whether that apparent stability is consistent with an incentivecompatible premium schedule. In a sense, we are elaborating on the old joke: "Sure, it works in practice, but could it work in theory?" because developing the theory that fits with practice may further illuminate both.

Our approach follows and extends the work of Hendel and Lizzeri [2003] for term life insurance. They do not deal with guaranteed renewability per se (despite its very common presence in term life insurance markets [Harrington and Niehaus, 1999]), but instead use the more explicit insurer commitment to future premiums present in policies with different lengths of term. We show that essentially the same results can be obtained with guaranteed renewability and single-year policies, and we go beyond Hendel and Lizzeri in providing direct comparisons of the extent of "front-loading" of actual premiums paid with an estimate of the optimal age-path of premiums.

The existence of GR features can also help to explain a seeming paradox in the relationship between nongroup insurance premiums actually paid and risk. The nongroup insurance market is thought to tailor premiums to risk, but in our previous research, we 
discovered that, although insurance premiums increase with age, the increase is much less than proportional to the increase in expected expenses with age [Pauly and Herring, 1999; Herring and Pauly, 2001]. Expected expenses approximately quadruple between the ages of 25 and 60 , but paid premiums (for the same level of coverage) increase only about two-and-a-half times. Moreover, we could not detect a statistically significant relationship between one's risk level, given one's age, and the premiums paid. But such a dampening of the age-related pattern of premiums is exactly what would be predicted if GR were in effect and insurers were pricing rationally. ${ }^{1}$ And if renewability were guaranteed at average premiums regardless of risk, premiums would be unrelated to risk for those who renew. One implication of this is that what an insurer would charge a 50-year-old applying for new insurance will generally be more than what the average 50-year-old, protected by GR, pays for "old" renewed insurance.

\section{I.B. Overview}

In this paper, we explicitly estimate the age profile of a GR premium schedule predicted by the theory outlined above, using the individual-level data in the Medical Expenditure Panel Survey (MEPS). We estimate expected medical expenses based on age, gender, and health status. We then consider a benchmark insurance policy, and we "piece together" the ideal GR premium schedule for that policy which will cover lifetime expected claims for both low-risk and high-risk individuals yet will provide an incentive for the low-risk individuals to remain with the policy. We also compare this GR premium schedule we estimate to actual nongroup insurance premiums from the Community Tracking Study's Household Survey. We then examine consumers' willingness-to-pay for this GR feature by producing estimates of both the benefits from avoiding the uncertainty of future-period risk-rated premiums and the "capital constraint" 
cost associated with the prepayment of GR premiums. Finally, we make some general observations about the feasibility of GR health insurance based upon our findings.

Since incentive-compatible guaranteed renewable premium schedules require an insurer to collect prepayments in order to cover the future claims of high-risk individuals (in excess of the claims of low-risk individuals), our model needs to account for projected growth rates in medical costs over time. Even though the premium can be increased to keep up with "pure" medical spending growth for the lower risks who are retained in the pool, the prepayments also need to cover anticipated spending growth for the higher risks above that for the lower risks. We do not, however, consider the case in which there are ex post realizations of cost growth which differ from the ex ante forecasts made, thereby creating unpredictable losses or gains to the

insurer. $^{2}$ We do however comment on the magnitude of this non-diversifiable risk and make a suggestion for potential diversification. One other aspect of long-term contracting in health insurance which we do not consider in this paper is the enforceability of such long-term contracts; there exists the potential for unscrupulous insurers to engage in either "reunderwriting" high-risk individuals or canceling a block of business in order to screen out highrisk individuals from new policies. ${ }^{3}$ We assume below that, because of effective regulation, reputation effects, or the threat of legal action, insurers do not violate their insurance contracts.

\section{METHODS AND MAIN RESULTS}

\section{II.A. Estimating Expected Expense}

We use data from the 1996, 1997, 1998, and 1999 Medical Expenditure Panel Surveys (MEPS) to produce individual-level estimates of expected expense for individuals of various ages and health risk levels. The MEPS is a nationally-representative household survey 
containing detailed information on demographic characteristics, health conditions, insurance status, and medical expenses. We first identify a pooled sample of 33,884 privately-insured individuals ages 18 to 64 from the four survey years, and we inflate each year's expenditure data to 2003 dollars using the annual growth rates for both private out-of-pocket payments and private health insurance payments identified by the National Health Expenditures data from the Centers for Medicare and Medicaid Services; these growth rates are presented in Heffler et al. [2003]. Since individuals in the MEPS held various types of plans with different cost-sharing provisions, we apply the American Academy of Actuaries [1995] induction methodology to standardized each individual's expenditures (i.e., total expenses, benefits, and out-of-pocket payments) to a benchmark plan, assumed to have a $\$ 200$ deductible, 25 percent coinsurance, and a $\$ 2500$ outof-pocket maximum.

We then use these data on actual insurance benefit payments to estimate individual-level expected benefits using a two-part regression model. ${ }^{4}$ The first part is a logistic regression model predicting the probability of having any nonzero benefits, and the second is an OLS model predicting (untransformed linear) benefits for the sample of those with nonzero benefits. ${ }^{5}$ The individual characteristics include binary variables for five-year age intervals interacted with gender and binary variables identifying the absence of any prior chronic conditions or the presence of the following twelve different medical conditions: cancer, diabetes, emphysema, high cholesterol, hypertension, heart disease, stroke, arthritis, asthma, gall bladder disease, stomach ulcer, and back problems. The MEPS identifies the year each of these conditions was discovered, and since we are interested in obtaining forecasts of expected expense using preexisting conditions, we include indicators for only those conditions that were discovered prior to the survey year. ${ }^{6}$ Because high risks on average either die relatively soon after their conditions 
are discovered or recover from their illnesses, the median period of unusually high expenses is only about four years [Eichner, McClellan, and Wise, 1998]. (Obviously some people who become high risks do remain that way for a longer period of time.) For this reason, we identify each of the twelve conditions in our regression model by whether it was discovered less than five years ago or more than five years ago.

The results from this regression analysis are presented in Table 1. The second column of this table shows mean statistics for the privately-insured MEPS sample, the third column shows results for the logistic regression model predicting any insurance benefits, the fourth column shows OLS results for untransformed "conditional" insurance benefits, and the final column shows a "simulated" marginal effect from combining the logistic and OLS estimates. (We determine this combined marginal effect for each variable by producing individual-level estimates of expected expense for the entire sample both "turning on and off" the relevant variable; the marginal effect for that variable is then the difference in mean expected expenses for the two samples.) The coefficients on age suggest that, even after controlling for higher expenses related to the presence of a high-expense condition, expected expense increases with age (aside from the slight decrease in expense for women after child-bearing age). Moreover, the results also demonstrate the dampening of the magnitude of condition-related expenses over time for many of the conditions. That is, a more-recent condition's marginal effect on expected expense is often higher than a less-recent condition's marginal effect on expected expense; these patterns of a diminishing effect for most conditions with time are much less dramatic than what would be observed if we included the conditions discovered during the survey year. However, for a few conditions, particularly stroke and gall bladder disease, the pattern of condition-related expense over time is the reverse. 


\section{II.B. Hypothetical Age-Related Premium Schedules and the Distribution of Risk}

Using the predicted values from these two regression models shown in Table 1, we produce estimates of expected expense based upon an individual's age, gender, and health status. After incorporating administrative loading equal to 30 percent of the premium, this expected expense measure represents how risk-rated "spot market" insurance premiums (albeit rated by the set of risk characteristics identified in our empirical model) for our benchmark plan would appear. ${ }^{7}$ Since our theoretical interest is in the schedule of renewable premiums for individuals who are all initially low risk, we exclude from the analysis individuals whose high-risk condition was discovered before the age of 18 ; the MEPS data indicate that only 2.5 percent of eighteenyear-olds have one or more preexisting conditions.

Since the total number of high-risk individuals is (by definition) small, we increase the sample size for our subsequent analysis by using the full sample of non-elderly adults (regardless of their current insurance status) in the MEPS with non-missing data, producing a distribution of expected benefits as if the full non-elderly adult sample was insured by the benchmark plan. Since the number of high-risk observations is still somewhat limited for any given age, the estimates we present below use a weighted average of the surrounding ages to produce "smoother" patterns. Specifically, observations within seven years in age are used, but they are given a weight inversely proportional to the number of years' difference between the observation and the specific age being estimated. The size of our resulting sample is 57,282 individuals.

Figure 2A and Figure 2B show the resulting estimated age profile of hypothetical lowrisk and high-risk premiums for females and males respectively. The premiums for each age are shown in 2003 dollars. Single-period risk-rated premiums would be less than $\$ 1000$ for younger 
low-risk males and about $\$ 3000$ for older low-risk males, but average about $\$ 2500$ for younger high-risk males and about $\$ 7000$ for older high-risk males. It should be noted that these hypothetical "high-risk" premiums shown here are actually averages of the different rated premiums high-risk individuals would face based on the number and nature of their high-risk conditions. The profile for average expense (from both low-risk and high-risk individuals together) by age is also shown. The premium schedule represents how a "modified community rating" (i.e., permitting rating by age but not by health status) premium schedule would appear.

We then examine in more detail how the number of high-risk individuals increases. The first row of Table 2 shows the proportion of the population who are high-risk by age; for simplicity, we present six selected ages at (roughly) ten-year intervals. Approximately a quarter of both males and females (who are all initially low-risk at age eighteen) have developed a highrisk condition by age 55, and almost 40 percent are high-risk by age 64 .

Estimating the probability that a low-risk individual develops a high-risk condition during any given year that is implied by these estimates, however, needs to take account of deaths. Since deaths occur more frequently to people with high-risk conditions, the per-period probability of becoming high-risk is larger than the value that would result from examining a static population without deaths. To be specific, the annual probability of a low-risk individual becoming high-risk during age $T$ can be expressed by the following:

$$
\left.P_{H, T}=\left(N_{H, T+1}-\left(1-D_{H, T}\right) N_{H, T}\right) /\left(1-D_{L, T}\right) N_{L, T}\right),
$$

where $N_{i, T}$ is the number of individuals of risk-type $i$ at age $T$, and $D_{i, T}$ is the mortality rate of risk-type $i$ at age $T$.

We produce a "standardized" population by adjusting the "point-in-time" MEPS sample weights (which fluctuate, for example, with the presence of the "Baby Boom" population) using 
age/gender mortality rates from the National Center for Health Statistics [Anderson, 1999]. By age 64, a cohort of 100 low-risk males will have had about 21 deaths, so that there will be about 47 low-risk members and 32 high-risk members remaining. We use MEPS data for deaths that occurred within the sample to determine the ratio of low-risk to high-risk mortality, $D_{i, T}$, for several selected age cohorts. We apply this ratio to the NCHS age/gender mortality rates to determine age/gender/risk mortality rates needed to estimate the above expression for $P_{H, T}$.

The remainder of Table 2 shows the results from these calculations. Conditional on age, mortality rates for high-risk individuals are almost ten times as high as mortality rates for lowrisk individuals. The resulting annual likelihood of a low-risk individual developing a high-risk condition is less than 0.5 percent in the early stage of life but increases considerably to over 2.5 percent in the later stage of life. The estimates presented in this table have two direct implications for the gradient of the GR premium schedule. The first is that many of those who develop a high-risk condition in their earlier years will die rather than continuing to incur high claims. The second is that the pre-payment necessary to cover future claims for the younger cohorts is decreased by the relatively fewer individuals developing high-risk conditions during the earlier stages of life.

\section{II.C. The Ideal Renewable Premium Schedule}

Now consider the breakeven GR premium schedule implied by the theoretical work of Cochrane [1995] and Pauly, Kunreuther, and Hirth [1995]. These models specify that the premium at age $T$ equals the low-risk expected expense at age $T$, plus the expected lifetime difference between low-risk and high-risk expected expense for all those individuals who become high-risk during age $T$. That is, the GR premium in each period is front-loaded by an 
additional amount that essentially insures the financial consequences (until the person goes on Medicare at age 65) of becoming high-risk during the period. For example, the premium at age 64 is simply equivalent to the low-risk expected expense at age 64. (All individuals who are high-risk before age 64 will have already covered their excess claims through prior front-loaded premiums.) The premium at age 63 is the sum of the low-risk expense at age 63 plus the difference in expected expense between high-risk expected expense and low-risk expected expense at age 64 for the cohort of 63-year-old low-risks who become high-risk during age 63 and are still alive at age $64 .^{8}$

As a result, low-risk individuals in any given year have no incentive to exit the pool of individuals covered by the GR policy for the risk-rated competitive "spot market" since the sum of their remaining expected lifetime GR premiums equals the sum of their remaining expected lifetime risk-rated premiums; an important assumption we make is that each consumer has the ability to predict what his or her feasible set of remaining premiums in this risk-rated spot market is, given his or her current health status, and makes a rational decision to either remain in or exit the GR pool. High-risk individuals, of course, also have no incentive to leave the GR pool for risk-rated insurance since the GR premium schedule is much lower. Moreover, even if some low-risk individuals did leave the GR pool for other reasons, their departure would not affect the insurer's ability to cover its future high-risk claims, since the funds for this purpose have already been prepaid by all insureds.

As discussed above, many individuals developing a high-risk condition may eventually recover from their illness-generally within five years, if at all. What matters for the incentivecompatibility criteria to hold is only whether any individual gains by exiting the pool. A formerly high-risk person who has recovered from a condition will have a lower expected 
expense than a person still suffering from that condition, but it is highly unlikely that the expected expense for individuals who have recovered from a condition is actually lower than the expected expense for low-risk individuals who have never had a high-risk chronic condition. ${ }^{9}$ In other words, if the GR premium schedule is low enough so that a low-risk individual will not exit the pool to seek a risk-rated policy, it must be low enough for a formerly high-risk recovered individual not to exit either.

It is not a problem that we cannot obtain separate estimates of expected expense for recovered individuals and non-recovered individuals for those whose condition is more than five years old. Determining the average of the two is sufficient because the excess premium that must be collected at age $T$ is the sum of the lifetime difference in future expected expenses for all those developing a condition in $T+1$ : those who recover, those who die after a time, and those who remain chronically ill. This sum is the same whether it is comprised by the sum of the average excess expected expenses (of both recovered and non-recovered individuals) essentially estimated by our regression model, or by the sum of lower recovered individuals' average expense and higher non-recovered individuals' average expense. However, there will be an overall effect of illness recovery on the steepness of the optimal GR premium schedule, since the average per-period expected expense for recovered and non-recovered individuals combined (i.e., the "more than five years" measures) is often lower than the expected per-period expected expense for newly-discovered conditions (i.e., the "one to five years" measures). The future high-risk claims for the former are more concentrated in the younger cohort's premiums while the future high-risk claims for the latter are more concentrated in the older cohort's premiumsimply because an older individual has less time to recover before the age of 64 . 
Finally, it is necessary to incorporate the overall growth in medical costs over time into our model. GR policies typically stipulate that premiums can increase for all insured individuals within a rating class (the rating class we consider is the entire set of initially low-risk eighteen year olds). Therefore it will be possible for the insurer to increase a "predetermined" schedule of premiums to reflect changes in medical prices and available technology. However, since an incentive-compatible GR premium schedule must also be priced such that low-risk individuals wish to remain in the GR pool, the "class-average" increase in the GR premium can reflect only the currently low-risks' growth in expenses. Therefore, it is necessary to apply a projected growth rate to the excess claims (i.e., the difference between high-risk and low-risk expense) incurred in periods $T+1, T+2, \ldots, 64$ for individuals who become high risk during period $T$ to be set aside in reserve.

We use the projected growth rates for private health insurance from the National Health Expenditures data from the Centers for Medicare and Medicaid Services (CMS), given in Heffler et al. [2003]. Specifically, CMS projects premium growth equal to 7.7 percent per year for the period 2004-2008 and 6.9 percent per year for the period 2008-2012. We assume that the 6.9 percent growth rates prevails for the years beyond 2012, and we also assume that the growth rate is proportional to low-risk and high-risk costs alike. Finally, we assume that insurers can earn a three percent real rate-of-return on these early-life "overcharges" set aside in reserve. Hence, the excess cost-inflated prepayment we estimate is actually a discounted value. That is, we assume that an insurer has to only collect $\$ 100$ in excess premiums today, for example, to pay out $\$ 103$ in excess claims during the next year-while this $\$ 103$ in $T+1$ claims are essentially equivalent to $\$ 96$ in claims in time $T$ due to medical cost inflation. 
Figure 3A and Figure 3B graph the incentive-compatible breakeven GR premium schedule we estimate, for females and males, respectively; Table 3 shows the magnitude of the premiums for several selected years. The premiums for each age are shown in 2003 dollars. These figures illustrate that the GR premium schedule generally increases with age, despite the prepayment necessary to cover future high-risk claims; the main exception to this trend is the decrease in the GR premium for women after the peak child-bearing age. The prepayment required (i.e., the difference between the future claims of newly high-risk individuals and lowrisk individuals) per year for the GR feature averages about $\$ 950$ for both males and females, and is relatively level throughout one's lifetime until it begins to taper off during the fifteen years before age 65 . Over the course of one's lifetime, this prepayment required for the GR feature is about 50 percent above the low-risk premium which averages about $\$ 1800$ for males and females

of all ages; however, this ratio of the prepayment to the low-risk expense decreases considerably over time since the low-risk expected expense increases with age. For males ages 18 to 34 the prepayment required is about $\$ 1050$ per year which is about 175 percent above this young male cohort's low-risk premium averaging \$600. For females ages 18 to 34 the prepayment required is about $\$ 1200$ per year which is about two-thirds of this cohort's low-risk premium averaging $\$ 1775$.

\section{II.D. Comparison to Actual Nongroup Premiums}

We next compare our estimated GR premium schedules to actual data for nongroup insurance premiums. The data sources for these premiums actually paid are the nationallyrepresentative 1996-1997 and 1998-1999 Community Tracking Study’s (CTS) Household Surveys. The sample we use consists of all of the persons with single-coverage nongroup plans 
$(\mathrm{N}=1589)$ identified in these two surveys. We make no adjustment for variation in generosity between these plans and our hypothetical benchmark plan, for whether a person is initiating or renewing coverage, for variation between the generosity of plans chosen and age-related expected expense, nor for state-level rating regulations. However, we do adjust for growth in premiums both between 1996 and 2003 and between 1998 and 2003 using the CMS growth rates for private health insurance premiums, so that we present these CTS nongroup premium data in 2003 dollars.

These mean nongroup premiums by age from the CTS data are shown in Figures 4A and 4B for females and males, respectively; Table 3 shows the magnitude of these CTS premiums for several selected years. While we have no objective measure of comparing the gradient of our hypothetical premium schedules with the premium schedule from actual nongroup purchases, there does appear to be surprising consistency between the age profile of actual nongroup premiums and the GR premium schedule we estimated. Nongroup premiums do not increase proportionately with average age-related expense, and the magnitude of these premiums tapers off considerably during the ten years before Medicare eligibility. ${ }^{10}$ However, since the CTS premium schedule also happens to be similar in shape to the low-risk premium schedule (because the expected expenses for those who remain low-risk also increases less rapidly with age than do average expected expenses), an alternative hypothesis would be the existence of strict underwriting to exclude all high-risk individuals from nongroup insurance. The publiclyavailable version of the CTS survey does not contain information on specific chronic health conditions but does contain self-reported health status: 7.8 percent of individuals between age 18 and 64 with employment-based health insurance report their health as fair or poor, while 7.0 percent of the nongroup insured sample report their health as fair or poor. Such strict 
underwriting to exclude all high risks from our nongroup sample, therefore, is not likely. While the existence of underwriting may have some effect on the pattern on nongroup premiums we observe, we conclude that the pattern of actual premiums is consistent with the hypothesis that insurers are actually charging lifetime GR premiums.

\section{II.E. GR Premium Schedules Under Alternative Assumptions}

One important influence on the magnitude of the prepayment necessary to fund the GR feature is the assumption made about the rate-of-return that insurers can earn on the early-life overcharges set aside in reserve. We assumed a modest three percent rate-of-return for the breakeven GR premium schedule shown above, but higher expected rates-of-return would obviously result in a lower amount of front-loading necessary. For purposes of illustration, we estimate breakeven GR premium schedules resulting from assuming that the rate-of-return insurers earn on reserves simply equaled the expected growth in medical expenditures; these schedules are shown in Figures 5A and 5B for females and males, respectively, and Table 3 shows the premiums for selected years. This alternative assumption about the rate-of-return lowers the average prepayment across all ages from about $\$ 950$ to about $\$ 525$ per year and decreases this amount by a relatively higher amount for younger individuals.

A second important influence on the degree of necessary front-loading is enrollee turnover. In real insurance markets relatively few people buy an individual insurance policy at a young age and stick with it until they go on Medicare. The turnover in the individual market is relatively high, especially because people move back and forth between the individual and (taxsubsidized) group markets. Such turnover makes GR less valuable to consumers on average, but 
it would also make the policy cheaper since insurers would not have to collect as much money to set aside in reserve for high-risk individuals.

To illustrate this point, we assume that a small fraction of individuals will leave the plan each year due to exogenous shocks but that the likelihood of leaving, given such a shock, is lower for those who have become high-risk. Specifically, we first assume that the median length of stay in the plan is five years for low-risk individuals and twenty years for high-risk individuals; that is, we assume a per-period probability of leaving the plan equal to approximately 3.402 percent for high-risk individuals. The resulting GR premium schedule for this "low turnover" scenario is shown in Figures 5A and 5B and in Table 3; this set of assumptions lowers the average prepayment of the GR feature above the low-risk expected expense from about $\$ 950$ to about $\$ 600$ with (as expected) a larger effect on decreasing the degree of front-loading for younger individuals.

We also consider a "high turnover" scenario in which we assume the median stay for high-risk individuals is only ten years by assuming their per-period probability of leaving the plan equals 6.693 percent. This increased turnover would result in GR premiums schedule with the average prepayment necessary to cover future claims lowered to about $\$ 400$. A fuller analysis incorporating consumer turnover is not possible here, but the main implication we want to note is that, in practical terms, the "horizon" that insurers typically take into account in thinking about and pricing GR is usually five to at most ten years, and so these illustrative breakeven GR premium schedules which incorporate turnover may be closer to reality than the hypothetical ones presented earlier. 


\section{OTHER ISSUES}

\section{III.A. Consumer Willingness-to-Pay for GR}

Up to this point, we have examined breakeven GR schedules that cover lifetime insurer costs and only ensured that low-risk consumers are indifferent between the future costs of the GR schedule and their expected future costs of alternative risk-rated schedules. On the one hand, risk-averse insureds would in principle be willing to pay more than the cost for something that protected them from uncertainty. On the other hand, Frick [1998] has argued that capital market imperfections may limit a younger individual's ability to afford the excess front-loading that must be collected. Thus, consumers might react by choosing policies without GR. Is this likely to happen? One way to answer this question is to estimate the valuation of the reduction in uncertainty associated with the GR feature and compare it with an estimate of the "costs" of assumed capital market constraints. The sum of these two components is then the net utility gain or loss from GR.

The benefit to consumers is the reduction in the uncertainty associated with random future-period premiums that one would face in a risk-rated spot market in the absence of GR insurance. The value of this benefit can be estimated as $1 / 2 A P \operatorname{var}(P)$, where $A P$ is the ArrowPratt absolute risk-aversion coefficient and $\operatorname{var}(P)$ is the variance of the alternative set of riskrated premiums one faces. (See, for example, Feldman and Dowd [1991] for a derivation of this expression.) Marquis and Holmer [1986] produced estimates of the Arrow-Pratt absolute riskaversion coefficient of 0.0011 and 0.00084 in 1982 dollars. Taking the average of these two estimates and multiplying it by the ratio of the 1982 CPI (100.00) to the 2003 CPI (188.29) taken from the Bureau of Labor Statistics [2003] gives an estimate of the Arrow-Pratt absolute riskaversion coefficient equal to 0.00052 in 2003 dollars. 
The relevant uncertainty a low-risk individual faces at age $T$ is the variation in futureperiod wealth related to becoming high risk during age $T$. (The variation in future premiums for a low-risk individual opting out of the GR pool before age $T$ that would result from becoming high risk during age $T+1$ or later is not included in the measure for age $T$, so as to not "double count" the gain in utility from the GR feature.) Specifically, for age $T$, we identify the distribution of risk-rated premiums an individual who is low-risk at age $T$ faces in each remaining year (i.e., $T+1, T+2, \ldots, 64)$ if that individual either stayed low-risk or became highrisk during age $T$. As before, the set of future premiums are inflated according to the CMS projections in private health insurance premiums. We then estimate the variance for each of these 64 - $T$ years faced at age $T$, use each computed variance to estimate that year's ArrowPratt valuation of uncertainty, and calculate the total discounted sum to give the value for age $T$. (The consumer discount rate we use is discussed below.)

Now consider the "capital constraint" cost resulting from the prepayment of future-period excess claims from high-risk individuals. That is, there is an opportunity cost to the consumer of foregone consumption associated with the prepayment of the GR feature; however, this opportunity cost is offset by the return-on-investment that insurers earn on their reserves. We generate two sets of results by assuming that the magnitude of the consumers' discount rate equals five percent and ten percent. ${ }^{11}$ These consumer discount rates are applicable not only to the capital constraint cost, but also to individuals' valuation of each future-period's reduction in uncertainty; the more myopic individuals are, they will place less emphasis on reductions in the variation in wealth which occur farther in the future.

Figures 6A and 6B show estimates for the willingness-to-pay for the GR feature, for females and males respectively, assuming a consumer discount rate of five percent; the top panel 
of Table 4 presents mean values for these estimates by age range. With a relatively low discount rate, the per-period valuation of the reduction in uncertainty averages about $\$ 2100$ for females and about $\$ 2200$ for males; for both females and males, the valuation of the reduction in uncertainty is slightly larger for the middle-aged cohort relative to the younger cohort, but it decreases considerably for the older cohort. Although younger individuals face a potentially longer lifetime of high premiums if they develop a chronic condition while young, the relatively level pattern for the valuation in risk with age seems to be driven primarily by the higher perperiod probability of becoming high-risk condition as age increases. The capital constraint cost associated with the prepayment of premiums averages about $\$ 250$ for both females and males. This capital constraint cost decreases with age similarly for both females and males. As a result, the net utility gain of the breakeven GR schedule averages about $\$ 1850$ for females and $\$ 1950$ for males. For both females and males, the net utility gain is always positive and relatively level across all ages, although it is highest for the middle-aged cohort. Thus, for all individuals, even with a relatively low discount rate of five percent, the value of the GR feature is quite high.

Figures $7 \mathrm{~A}$ and $7 \mathrm{~B}$ and the bottom panel of Table 4 show the estimates of the utility gain from the breakeven GR premium schedule if the discount rate is assumed to be a higher value equal to ten percent. The higher discount rate both decreases the valuation of the reduction in uncertainty (from about $\$ 2150$ to about $\$ 1200$ ) and increases the magnitude of the capital constraint cost (from about $\$ 250$ to about $\$ 550$ ), thereby decreasing the net utility gain from the GR feature to between $\$ 650$ and $\$ 675$. The higher discount rate has the largest impact on the younger cohort; this is driven primarily by the significant decrease in the valuation of uncertainty resulting from having relatively less concern with fluctuations in future-period risk-rated premiums in the spot market. The net utility gain from the GR feature becomes negligible for 
younger females, while it actually becomes negative for younger males, averaging about $-\$ 150$, although the net utility remains positive for older individuals. Therefore, under this set of assumptions, males under the age of 30 would not be willing to purchase this breakeven GR policy, since the capital constraint cost exceeds the valuation of the reduction in uncertainty.

These calculations for consumers' willingness to pay for the GR feature imply that consumers would be willing to pay a premium at each age equal to the sum of the breakeven GR premium and the net utility gain from the GR feature. However, this does not imply that there is actually a range of feasible GR premium schedules that could exist. Bertrand price competition by insurers implies that the breakeven GR premium schedule we have estimated is the unique equilibrium that will exist in the market. An insurer could not offer an alternative premium schedule with lower younger-age premiums subsidized by higher older-age premiums, since the low-risk older insureds will be attracted to other insurers offering the breakeven GR premium schedule. However, the possibility that the net utility gain of the GR feature for younger individuals is not positive (e.g., males under the age of 30 assuming a 10 percent discount rate) does not imply that GR policies will cease to exist for all consumers. Rather, GR policies (whose premiums schedule will be equivalent to the breakeven GR schedule we have estimated) would exist for the cohort of low-risk consumers for whom both the current and future utility gains are nonzero (e.g., low-risk 30 year-old males).

\section{III.B. Lifetime Non-Medical Consumption Smoothing}

An alternative way of examining the possible role of capital constraints builds on Frick's [1998] insight that individuals should generally seek to smooth lifetime consumption, but the typical pattern of lifetime savings combined with capital constraints limits their ability to do so. 
If we think of the relevant consumption as total spending minus medical insurance premiums, the pattern of premiums (which are lower when younger) is offset by the typical earnings pattern (which is also lower when young). But would the average age-related expense or the GR premium schedule produce a smoother pattern of non-medical consumption?

To address this question, we obtain data for total annual income from the March 2002 Current Population Survey (CPS) for fulltime workers, and inflate these amounts to 2003 dollars. ${ }^{12}$ Table 5 describes the feasible consumption patterns assuming neither borrowing nor lending for a typical production worker. Specifically, we show the non-medical consumption (i.e., total income minus the premium) as a percentage of total income for both the age-rated premium schedule and the breakeven GR premium schedule. For both males and females, the non-medical consumption resulting from an age-rated premium schedule is relatively level during the younger ages but then decreases considerably during the ten-to-fifteen years before Medicare eligibility. Alternatively, the non-medical consumption resulting from the breakeven GR premium schedule is lowest when workers are young (coinciding when these youngest workers earn much lower incomes) and then relatively level during the middle and older ages.

However, since the breakeven GR premium schedule under consideration includes prepayments for future medical claims incorporating medical cost growth rates, it is not entirely appropriate to compare this GR premium schedule (deflated to 2003 dollars) that an individual faces to current levels of income (as opposed to growing incomes, albeit growing less rapidly than medical services costs) and age-rated premiums for other cohorts. Therefore, in the bottom panel of Table 5, we present expected lifetime income and premium amounts for a cohort of eighteen-year-old individuals looking towards the future. For these estimates, we assume annual three percent growth in income (relative to older cohorts' current levels of income) and use the 
CMS growth rates for private health insurance premiums described above. Although the GR premiums schedules generate relatively lower levels of non-medical consumption at the youngest age, the GR premium schedule produces a much more smooth level of future non-medical consumption than does the age-rated premium schedule.

\section{III.C. Underwriting and GR}

We have assumed to this point that the population of potential insurance purchasers consists of low risks. This is approximately true at young ages. Less than ten percent of people in their twenties have a pre-existing medical condition. If the process of underwriting is costly to insurers, it may even be the case that the costs of screening younger applicants for many highrisk conditions would outweigh the consequences resulting from adverse selection, and hence it is conceivable that almost all young applicants would be enrolled. If the purchase of insurance is contemplated at an older age, however, we would expect to see underwriting to screen out highrisk applicants. Since the optimal GR premium schedule is defined by the incentivecompatibility of low-risk individuals at each age, older low-risk applicants could join an existing GR pool and pay the same future premium schedule. High-risk applicants who are underwritten would face higher premiums but could still perhaps take advantage of an alternative GR feature. Since risk level is actually a continuum, it is conceivable that a population of middle-age applicants who are moderate risk (e.g., one pre-existing conditions) could form their own GR pool to insure against the uncertainty of becoming even higher risk (e.g., two or more preexisting conditions). 


\section{III.D. Forecasting Future Growth in Spending}

As noted earlier, a potential problem with GR contracting is the magnitude and uncertainty of future medical spending. This risk is alleviated somewhat by the "renewal at class-average rates" feature, but since the incentive-compatible GR feature involves prepayment of future claims for high-risk individuals, some potentially non-diversifiable risk to the insurer will remain. This remaining risk is essentially the spread between forecasted and realized cost growth times the proportion of the claims subject to this risk, which we estimate to be about 35 percent-based upon an average GR prepayment of $\$ 950$ (which is subject to this uncertainty) and an average low-risk expense of $\$ 1800$ (which is not subject to this uncertainty).

High unanticipated medical cost growth (thereby resulting in a plan having undercharged and under-reserved) could explain the practice of terminating rating classes without attributing such observed behavior to an "underhanded" motive. That is, suppose that an insurer had incorrectly underestimated future cost growth where the higher growth actually occurred, and it adjusted the subsequent period's premium upward — for both low-risk and high-risk individuals - to simply cover the increase in costs resulting from excess claims from high-risk individuals. For how long would the adjusted premium still appeal to low-risk individuals (since they have a net utility gain from the GR feature) before (potentially) increasing too much? To address this question, we consider an insurer's naïve GR premium schedule resulting from its simply assuming three percent growth in medical expenditures offset by its three percent rate of return on its reserves. We then assume that the insurer adjusts the initial naïve GR premium schedule upwards in each subsequent year to pay for the unanticipated cost growth (assumed to ex post be seven percent). We observe how soon low-risk individuals would discontinue 
purchasing this adjusted GR plan—based upon when (or if, for that matter) the plan's necessary upward adjustment exceeds the individual's willingness-to-pay for the GR feature.

We first consider the willingness-to-pay associated with a five percent consumer discount rate; recall that this assumption generated a positive utility gain averaging about $\$ 1900$. For an initial cohort of eighteen year olds, an upwards-adjusted premium schedule to cover such unanticipated cost growth would actually remain incentive-compatible until age 43 for females and age 45 for males; after twenty-five years, low-risk individuals would no longer be willing to remain in this pool. We then consider the willingness-to-pay associated with a ten percent discount rate; this assumption generated an average utility gain of just over $\$ 650$, but was generally negative for males and females in their twenties. Here we consider an initial cohort of thirty-five year olds (for whom the optimal breakeven GR premium schedule would be incentive-compatible). For this cohort, upwardly adjusting a naïve GR premium schedule would instead remain incentive compatible for only twelve years — specifically, until age 47 for females and 48 for males. After twelve years, individuals who remained low risk would no longer be willing to purchase the policy and this naïve insurer would have to cancel the rating class to avoid losing money.

However, as a modest proposal, we suggest that there may be a potential way in which an insurer could diversify this remaining risk related to "unforeseen" cost growth. It is likely that the profits of health care companies (e.g., for-profit hospital chains, pharmaceutical companies) are positively correlated with the rate of growth in medical spending. If this were the case, an insurer that invested its GR reserves into a portfolio of stocks of such companies should receive returns that are negatively correlated (and hence diversified) with the fluctuations in its own GR reserves set aside for future high-risk claims. 


\section{CONCLUSION}

This paper therefore draws optimistic implications for GR in individual health insurance. The feature is virtually universal even without regulation in term life insurance, so health insurers should be and probably are familiar with the need for some frontloading of premiums. But what is less clear is whether they are aware of the desires of the low risks who need to be kept in the pool. Despite the moderately low cost of the GR feature, younger individuals who place a high value on current levels of consumption may still not be willing to pay this low cost unless the breakeven GR premium is subsidized. Regardless, it does seem that existing breakeven schedules come reasonably close to optimal incentive-compatible patterns. 


\section{References:}

American Academy of Actuaries, 1995, Medical Savings Accounts: Cost Implications and Design Issues, AAA Public Policy Monograph.

Anderson, R., 1999, "U.S. Abridged Life Tables, 1996," in National Vital Statistics Reports 47.13. Atlanta, GA: Centers for Disease Control and Prevention's National Center for Health Statistics.

Bureau of Labor Statistics, 2003, Handbook of Labor Statistics. Washington, D.C.: U.S. Department of Labor.

Cochrane, J., 1995, “Time-Consistent Health Insurance," Journal of Political Economy 103.3, 445-473.

Cutler, D., 1993, “Why Doesn't the Market Fully Insure Long-Term Care?” NBER Working Paper \#4301.

Duan, N., et al., 1983, "A Comparison of Alternative Models for the Demand for Health Care," Journal of Business and Economic Statistics 1.2, 115-126.

Eichner, M., M. McClellan, and D. Wise, 1998, "Insurance or Self-Insurance? Variation, Persistence, and Individual Health Accounts," in D. Wise, ed., Inquiries in the Economics of Aging. Chicago, IL: University of Chicago Press.

Feldman, R., and B. Dowd, 1991, "A New Estimate of the Welfare Loss of Excess Health Insurance," American Economic Review 81.1, 297-301

Frick, K., 1998, "Consumer Capital Market Constraints and Guaranteed Renewable Insurance," Journal of Risk and Uncertainty 16, 271-278.

Harrington, S., and G. Niehaus, 1999, Risk Management and Insurance. New York: Irwin McGraw Hill.

Heffler, S., et al., 2003, "Health Spending Projections for 2002-2012," Health Affairs Web Exclusive Supplement 3, 54-65.

Hendel, I., and A. Lizzeri, 2003, "The Role of Commitment in Dynamic Contracts: Evidence From Life Insurance," The Quarterly Journal of Economics 118.1, 299-327.

Herring, B., and M. Pauly, 2001, "Premium Variation in the Individual Insurance Market," International Journal of Health Care Finance and Economics 1.1, 43-58.

Marquis, M., and M. Holmer, 1986, Choice Under Uncertainty and the Demand for Health Insurance. Publication Number N-2516-HHS. Santa Monica, CA: Rand Corporation.

Patel, V. and M. Pauly, 2002., "Guaranteed Renewability And The Problem Of Risk Variation In Individual Health Insurance Markets," Health Affairs Web Exclusive Supplement 2, 280289.

Pauly, M., and B. Herring, 1999, Pooling Health Insurance Risks. Washington, D.C.: AEI Press.

Pauly, M., H. Kunreuther, and R. Hirth, 1995, "Guaranteed Renewability in Insurance," Journal of Risk and Uncertainty 10, 143-156.

Pauly, M., A. Percy, and B. Herring. "Individual Versus Job-Based Health Insurance: Weighing the Pros and Cons," Health Affairs 18.6, 1999, 28-44.

Terhune, C., 2002, "Side Effect-Insurer's Tactic: If You Get Sick, the Premium Rises," Wall Street Journal 04-09-2002, A 20 


\section{Notes:}

${ }^{1}$ Even before the Health Insurance Portability and Accountability Act (HIPAA) of 1996 requiring guaranteed renewability of all nongroup insurers, many states had their own GR regulations in effect [Pauly, Percy, and Herring, 1999]. Although the HIPAA law is somewhat incomplete in that it does not require premiums to be the same for all individuals within a rating class, Patel and Pauly [2002] find, in a national survey of insurance regulators, that 47 states do have this requirement.

${ }^{2}$ Cutler [1993] has argued that such inter-temporal uncertainty in the costs of long-term care has resulted in a failure to completely insure nursing home care.

3 The practice of "re-underwriting" by a health insurer in Florida was highlighted a year ago in the Wall Street Journal [Terhune, 2002]. Although this article received a fair amount of attention, this practice is generally considered to be an anomaly within the industry.

${ }^{4}$ In principle, it would be possible to determine the premiums presented below by simply computing the average actual expense for the relevant sub-sample. However, we are primarily interested in producing estimates for high-risk individuals both as a function of their current age and the age at which their high-risk condition was first discovered. Since the reliability of such estimates from so many different small-size samples of high-risk individuals would be quite low, we use the following regression model instead.

5 We use a traditional two-part methodology for estimating expected expenses to handle the clustering of those with zero actual expense [Duan et al., 1983], but we decide not to use a transformed dependent variable in the second stage model estimating nonzero expenses. We have found that using untransformed linear expenses increases the model's ability to more accurately estimate the right tail of the expense distribution than using either logarithmic or square-root "smearing" models [Pauly and Herring, 1999; Herring and Pauly, 2001].

6 The year that an existing condition was discovered is missing for a fraction of the observations in the MEPS. (There is, however, complete data for whether an individual has ever been made aware by a physician about the condition.) Rather than delete these observations and re-weight those observations with non-missing data, we wish to retain as many high-risk observations in the data as possible; we therefore impute the date discovered for those with missing data using the age distribution of conditions discovered during the MEPS sample year.

7 We should note that neither the assumptions about the AAA induction methodology, the inflator parameter to generate expenses in 2003 dollars, nor the magnitude of the administrative loading affects the patterns of the resulting premium gradients by age. Instead these assumptions are made simply to generate overall magnitudes that appear realistic.

8 To be clear, the premium at age 62 is the sum of the low-risk expense for 62-year-olds plus the difference in lifetime expected expense between high-risk expected expense and low-risk expected expense (for both 63-year-olds and 64-year-olds who remain alive) for the proportion of 62-year-old low-risks who develop a condition during age 62 .

${ }^{9}$ We cannot verify this empirically with the MEPS, however, because it is not feasible to accurately distinguish ex ante a formerly high-risk recovered individual from a currently high-risk non-recovered individual with a two-year panel.

${ }^{10}$ One comparison can be made by regressing the average actual nongroup premium from the CTS on the age-related average expense and regressing the nongroup premium on the hypothetical GR premium schedule. Using logs for these measures to generate an elasticity estimate, the elasticity of actual premiums with respect to age-related average expense (in results not shown) was 0.45 for males and 0.57 for females, while the elasticity of the CTS premiums with respect to the GR premium schedule was 1.11 for males and 1.11 for females. This informal comparison implies that the slope of the GR premium schedule is considerably closer to the slope of the actual nongroup premium schedule than to the slope of age-related average expense.

11 If individuals have the same discount rate as insurers (i.e., three percent), the opportunity cost of the early-life "overcharges" will simply offset the return-on-investment that insurers earn on this money set in reserve. The net utility gain of the GR feature then would solely equal the benefit from the reduction in uncertainty.

${ }^{12}$ We thank Peter Joski for providing these estimates for income from the CPS. 
Table 1

Expected Expenses for Non-Elderly Insured Adults ${ }^{\mathrm{a}}$

\begin{tabular}{|c|c|c|c|c|}
\hline Variable & Mean & $\begin{array}{c}\text { Logistic }^{\mathrm{c}} \\
\text { Coefficient }\end{array}$ & $\begin{array}{c}\text { OLS } \\
\text { Coefficient }\end{array}$ & $\begin{array}{c}\text { Combined } \\
\text { Effect }\end{array}$ \\
\hline Total expenditures ${ }^{\mathrm{b}}$ & 1970.1 & & & \\
\hline Total benefits ${ }^{\mathrm{b}}$ & 1571.8 & & & \\
\hline Any positive benefits ${ }^{\mathrm{b}}$ & 0.558 & $-0.917^{* * *}$ & & \\
\hline Total nonzero benefits $^{\mathrm{b}}$ & 2816.1 & & $1486.7^{* * *}$ & \\
\hline Male ages 18 to 24 & 0.0554 & -0.004 & 24.3 & 7.0 \\
\hline Male ages 25 to 29 & 0.0461 & -0.121 & -228.2 & -114.8 \\
\hline Male ages 30 to 34 & 0.0585 & & & \\
\hline Male ages 35 to 39 & 0.0700 & $0.215^{* * *}$ & 103.3 & 116.0 \\
\hline Male ages 40 to 44 & 0.0735 & $0.262^{* * *}$ & 506.7 & 296.5 \\
\hline Male ages 45 to 49 & 0.0634 & $0.553^{* * *}$ & $777.8^{*}$ & 563.5 \\
\hline Male ages 50 to 54 & 0.0547 & $0.816^{* * *}$ & $1169.5^{* * *}$ & 916.4 \\
\hline Male ages 55 to 59 & 0.0385 & $0.894^{* * *}$ & $2263.7^{* * *}$ & 1565.2 \\
\hline Male ages 60 to 64 & 0.0303 & $1.344^{* * *}$ & $2575.3^{* * *}$ & 2158.9 \\
\hline Female ages 18 to 24 & 0.0554 & $0.889^{* * *}$ & 193.6 & 430.6 \\
\hline Female ages 25 to 29 & 0.0496 & $1.455^{* * *}$ & $833.3^{*}$ & 1086.6 \\
\hline Female ages 30 to 34 & 0.0612 & $1.349^{* * *}$ & $1132.6^{* * *}$ & 1226.5 \\
\hline Female ages 35 to 39 & 0.0707 & $1.200^{* * *}$ & $1175.9^{* * *}$ & 1164.0 \\
\hline Female ages 40 to 44 & 0.0762 & $1.310^{* * *}$ & $943.6^{* *}$ & 1081.9 \\
\hline Female ages 45 to 49 & 0.0671 & $1.443^{* * *}$ & $679.8^{*}$ & 977.6 \\
\hline Female ages 50 to 54 & 0.0579 & $1.781^{* * *}$ & $1013.0^{* *}$ & 1375.3 \\
\hline Female ages 55 to 59 & 0.0402 & $1.892^{* * *}$ & $1813.6^{* * *}$ & 2033.9 \\
\hline Female ages 60 to 64 & 0.0313 & $2.048^{* * *}$ & $2299.4^{* * *}$ & 2505.4 \\
\hline Cancer, one to five years ago & 0.0039 & $1.658^{* * *}$ & $12108.0^{* * *}$ & 10848.4 \\
\hline Cancer, more than five years ago & 0.0055 & $1.810^{* * *}$ & $6060.5^{* * *}$ & 5910.9 \\
\hline Diabetes, one to five years ago & 0.0061 & $2.014^{* * *}$ & $1653.5^{* * *}$ & 2215.0 \\
\hline Diabetes, more than five years ago & 0.0104 & $1.927^{* * *}$ & 697.0 & 1347.7 \\
\hline Emphysema, one to five years ago & 0.0007 & 0.751 & $4800.3^{* *}$ & 3718.9 \\
\hline Emphysema, more than five years ago & 0.0006 & 11.482 & -1653.0 & -653.2 \\
\hline High cholesterol, one to five years ago & 0.0070 & $1.697^{* * *}$ & 61.6 & 737.6 \\
\hline High cholesterol, more than five years ago & 0.0120 & $1.748^{* * *}$ & -312.6 & 432.6 \\
\hline Hypertension, one to five years ago & 0.0171 & $1.858^{* * *}$ & $763.9^{* *}$ & 1400.8 \\
\hline Hypertension, more than five years ago & 0.0364 & $1.664^{* * *}$ & -285.2 & 453.3 \\
\hline Heart disease, one to five years ago & 0.0047 & $2.255^{* * *}$ & $5687.6^{* * *}$ & 5935.9 \\
\hline Heart disease, more than five years ago & 0.0110 & $2.207^{* * *}$ & $4166.6^{* * *}$ & 4537.7 \\
\hline Stroke, one to five years ago & 0.0005 & 1.325 & 2911.1 & 2888.4 \\
\hline Stroke, more than five years ago & 0.0006 & 11.571 & $9860.3^{* * *}$ & 10860.4 \\
\hline Arthritis, one to five years ago & 0.0077 & $0.970^{* * *}$ & $1584.9^{* * *}$ & 1615.5 \\
\hline Arthritis, more than five years ago & 0.0153 & $1.083^{* * *}$ & $842.2^{* *}$ & 1125.9 \\
\hline Asthma, one to five years ago & 0.0018 & $0.962^{* * *}$ & $6029.9^{* * *}$ & 4880.9 \\
\hline Asthma, more than five years ago & 0.0152 & $1.246^{* * *}$ & $1171.0^{* * *}$ & 1460.6 \\
\hline Gall bladder disease, one to five years ago & 0.0006 & $2.812^{* * *}$ & $3475.2^{*}$ & 4147.8 \\
\hline Gall bladder disease, more than five years ago & 0.0007 & $1.576^{* *}$ & $6532.7^{* * *}$ & 6074.7 \\
\hline Stomach ulcer, one to five years ago & 0.0007 & 0.537 & 1126.8 & 1004.3 \\
\hline Stomach ulcer, more than five years ago & 0.0017 & $1.485^{* * *}$ & 987.1 & 1428.0 \\
\hline Back problems, one to five years ago & 0.0139 & $0.704^{* * *}$ & 509.2 & 685.6 \\
\hline Back problems, more than five years ago & 0.0331 & $0.791^{* * *}$ & $660.6^{* *}$ & 837.4 \\
\hline Number of observations & 33,884 & 33,884 & 18,652 & \\
\hline -2 Log Likelihood & & -40944 & & \\
\hline Adjusted R-squared & & & 0.0412 & \\
\hline
\end{tabular}

Source: 1996, 1997, 1998, and 1999 Medical Expenditure Panel Surveys.

p-values: Statistical significance at 0.01 or better $(* * *)$; between 0.01 and $0.05(* *)$; between 0.05 and $0.10(*)$

${ }^{a}$ Sample includes all privately-insured adults between 18 and 64, excluding those with public insurance.

${ }^{\mathrm{b}}$ Total expenditures are in 2003 dollars and are standardized to a benchmark plan; see text for details.

${ }^{\mathrm{c}}$ Model predicts the likelihood of having any positive insurance benefits.

${ }^{\mathrm{d}}$ Model predicts the magnitude of total benefits, conditional on having non-zero benefits. 
Table 2

Distribution of Low-Risk and High-Risk Individuals

\begin{tabular}{|c|c|c|c|c|c|c|c|}
\hline & \multicolumn{7}{|c|}{ Age: } \\
\hline & 18 & 25 & 35 & 45 & 55 & 63 & 64 \\
\hline \multicolumn{8}{|l|}{ Females: } \\
\hline Proportion that are high-risk & 0.0 & 3.9 & 8.5 & 16.6 & 27.5 & 38.4 & 39.4 \\
\hline Number that are alive $\mathrm{e}^{\mathrm{a}}$ & 100.0 & 99.7 & 98.9 & 97.5 & 94.3 & 88.7 & 87.7 \\
\hline Number that are low-risk ${ }^{\mathrm{a}}$ & 100.0 & 95.7 & 90.5 & 81.3 & 68.3 & 54.7 & 53.1 \\
\hline Number that are high-risk & 0.0 & 3.9 & 8.4 & 16.2 & 25.9 & 34.1 & 34.6 \\
\hline Probability of dying, low-risk ${ }^{\mathrm{b}}$ & 0.05 & 0.04 & 0.06 & 0.09 & 0.16 & 0.27 & $\mathrm{n} / \mathrm{a}$ \\
\hline Probability of dying, high-risk ${ }^{\mathrm{b}}$ & 0.44 & 0.38 & 0.57 & 0.83 & 1.48 & 2.49 & $\mathrm{n} / \mathrm{a}$ \\
\hline Probability of becoming high-risk ${ }^{\mathrm{b}}$ & 0.80 & 0.51 & 0.85 & 1.67 & 3.17 & 2.56 & $\mathrm{n} / \mathrm{a}$ \\
\hline \multicolumn{8}{|l|}{ Males: } \\
\hline Proportion that are high-risk & 0.0 & 3.0 & 7.9 & 15.3 & 26.9 & 38.4 & 39.3 \\
\hline Number that are alive $\mathrm{a}^{\mathrm{a}}$ & 100.0 & 99.0 & 97.2 & 94.3 & 88.9 & 80.3 & 78.8 \\
\hline Number that are low-risk ${ }^{\mathrm{a}}$ & 100.0 & 96.0 & 89.5 & 79.9 & 65.0 & 49.4 & 47.8 \\
\hline Number that are high-risk ${ }^{\mathrm{a}}$ & 0.0 & 3.0 & 7.7 & 14.5 & 23.9 & 30.8 & 30.9 \\
\hline Probability of dying, low-risk ${ }^{\mathrm{b}}$ & 0.13 & 0.12 & 0.14 & 0.18 & 0.28 & 0.46 & $\mathrm{n} / \mathrm{a}$ \\
\hline Probability of dying, high-risk ${ }^{b}$ & 1.16 & 1.12 & 1.28 & 1.67 & 2.55 & 4.18 & $\mathrm{n} / \mathrm{a}$ \\
\hline Probability of becoming high-risk ${ }^{b}$ & 0.41 & 0.54 & 0.78 & 1.64 & 1.93 & 2.80 & $\mathrm{n} / \mathrm{a}$ \\
\hline
\end{tabular}

Sources: 1996, 1997, 1998, and 1999 Medical Expenditure Panel Surveys. National Center for Health Statistics [Anderson, 1999].

${ }^{a}$ The MEPS sample weights are normalized to examine an initial population of 100 eighteen-year old females and 100 eighteen-year-old males. More details about the sample weight modification is presented in the text.

${ }^{b}$ The probabilities of dying and the probability of becoming high-risk are all annual rates; e.g., the probability of becoming high risk at age 25 is the likelihood of a low-risk 25 -year old individual developing a high-risk condition before age 26 . 
Table 3

Magnitude of Selected Premiums by Age ${ }^{a}$

\begin{tabular}{|c|c|c|c|c|c|c|}
\hline & \multicolumn{6}{|c|}{ Age: } \\
\hline & 18 & 25 & 35 & 45 & 55 & 64 \\
\hline \multicolumn{7}{|l|}{ Females: } \\
\hline Low-risk premium & 1208 & 1772 & 2187 & 2051 & 2985 & 4009 \\
\hline High-risk premium & $\mathrm{n} / \mathrm{a}$ & 5070 & 5168 & 5039 & 6680 & 8027 \\
\hline Age-rated premium & 1208 & 1902 & 2440 & 2548 & 4002 & 5594 \\
\hline GR premium & 2291 & 2955 & 3556 & 3043 & 3534 & 4009 \\
\hline CTS nongroup premium & 1638 & 1776 & 2135 & 2584 & 3205 & 3687 \\
\hline GR premium with higher return & 1605 & 2278 & 2923 & 2718 & 3444 & 4009 \\
\hline GR premium with low turnover & 1709 & 2390 & 3039 & 2783 & 3463 & 4009 \\
\hline GR premium with high turnover & 1454 & 2100 & 2718 & 2589 & 3402 & 4009 \\
\hline \multicolumn{7}{|l|}{ Males: } \\
\hline Low-risk premium & 611 & 540 & 711 & 1190 & 2254 & 3402 \\
\hline High-risk premium & $\mathrm{n} / \mathrm{a}$ & 1929 & 2838 & 4172 & 6603 & 8819 \\
\hline Age-rated premium & 611 & 582 & 879 & 1648 & 3424 & 5530 \\
\hline GR premium & 1536 & 1436 & 2048 & 2294 & 3005 & 3402 \\
\hline CTS nongroup premium & 1539 & 1712 & 1893 & 2727 & 3663 & 4143 \\
\hline GR premium with higher return & 892 & 894 & 1365 & 1932 & 2875 & 3402 \\
\hline GR premium with low turnover & 986 & 983 & 1488 & 2005 & 2902 & 3402 \\
\hline GR premium with high turnover & 762 & 756 & 1152 & 1788 & 2815 & 3402 \\
\hline
\end{tabular}

Sources: 1996, 1997, 1998, and 1999 Medical Expenditure Panel Surveys; 1996-1997 and 1998-1999 Community Tracking Study Household Surveys.

${ }^{\text {a }}$ Each premium is given in 2003 dollars. 


\section{Table 4}

Average Net Utility Estimates by Age Range

\begin{tabular}{|c|c|c|c|c|}
\hline & \multicolumn{4}{|c|}{ Age Range: } \\
\hline & $18-34$ & $35-49$ & $50-64$ & Entire \\
\hline \multicolumn{5}{|l|}{ Five percent discount rate: } \\
\hline \multicolumn{5}{|l|}{ Females: } \\
\hline Benefit: uncertainty reduction & 2274 & 2537 & 1424 & 2099 \\
\hline Cost: capital constraint & -414 & -247 & -38 & -245 \\
\hline Net utility & 1860 & 2289 & 1385 & 1853 \\
\hline \multicolumn{5}{|l|}{ Males: } \\
\hline Benefit: uncertainty reduction & 2037 & 2596 & 1947 & 2192 \\
\hline Cost: capital constraint & -405 & -258 & -54 & -254 \\
\hline Net utility & 1632 & 2338 & 1893 & 1938 \\
\hline \multicolumn{5}{|l|}{ Ten percent discount rate: } \\
\hline \multicolumn{5}{|l|}{ Females: } \\
\hline Benefit: uncertainty reduction & 908 & 1510 & 1230 & 1201 \\
\hline Cost: capital constraint & -847 & -602 & -112 & -543 \\
\hline Net utility & 62 & 908 & 1118 & 658 \\
\hline \multicolumn{5}{|l|}{ Males: } \\
\hline Benefit: uncertainty reduction & 657 & 1527 & 1651 & 1232 \\
\hline Cost: capital constraint & -813 & -625 & -158 & -559 \\
\hline Net utility & -157 & 902 & 1493 & 673 \\
\hline
\end{tabular}

Note: The methodology for these estimates is provided in the text; values are given in 2003 dollars. 
Table 5

Non-Medical Consumption as a Percentage of Income

\begin{tabular}{|c|c|c|c|c|c|c|}
\hline & \multicolumn{6}{|c|}{ Age: } \\
\hline & 18 & 25 & 35 & 45 & 55 & 64 \\
\hline \multicolumn{7}{|l|}{ Females: } \\
\hline Total income $(\mathrm{I})^{\mathrm{a}}$ & 13,686 & 27,443 & 37,525 & 40,112 & 41,478 & 36,531 \\
\hline Age-rated premium & 1,208 & 1,902 & 2,440 & 2,548 & 4,002 & 5,594 \\
\hline GR premium & 2,291 & 2,955 & 3,556 & 3,043 & 3,534 & 4,009 \\
\hline $\mathrm{C} / \mathrm{I}:{ }^{\mathrm{b}}$ average premium & 0.91 & 0.93 & 0.93 & 0.94 & 0.90 & 0.85 \\
\hline $\mathrm{C} / \mathrm{I}:^{\mathrm{b}}$ GR premium & 0.83 & 0.89 & 0.91 & 0.92 & 0.91 & 0.89 \\
\hline \multicolumn{7}{|l|}{ Males: } \\
\hline Total income $(\mathrm{I})^{\mathrm{a}}$ & 14,265 & 31,408 & 52,040 & 62,291 & 66,636 & 66,399 \\
\hline Age-rated premium & 611 & 582 & 879 & 1,648 & 3,424 & 5,530 \\
\hline GR premium & 1,536 & 1,436 & 2,048 & 2,294 & 3,005 & 3,402 \\
\hline $\mathrm{C} / \mathrm{I}:^{b}$ average premium & 0.96 & 0.98 & 0.98 & 0.97 & 0.95 & 0.92 \\
\hline \multirow[t]{3}{*}{$\mathrm{C} / \mathrm{I}^{\mathrm{b}}$ GR premium } & 0.89 & 0.95 & 0.96 & 0.96 & 0.95 & 0.95 \\
\hline & \multicolumn{6}{|c|}{ Year: } \\
\hline & 2003 & 2010 & 2020 & 2030 & 2040 & 2049 \\
\hline \multicolumn{7}{|l|}{ Females, currently age 18 : } \\
\hline Future total income $\left(\mathrm{I}_{\mathrm{f}}\right)^{\mathrm{c}}$ & 13,686 & 33,752 & 62,024 & 89,101 & 123,822 & 142,288 \\
\hline Future age-rated premium $^{\mathrm{d}}$ & 1,208 & 3,149 & 7,874 & 16,028 & 49,045 & 124,996 \\
\hline Future GR premium $^{\mathrm{d}}$ & 2,291 & 4,893 & 11,477 & 19,136 & 43,317 & 89,588 \\
\hline $\mathrm{C} / \mathrm{I}_{\mathrm{f}}{ }^{\mathrm{b}}$ future age-rated premium & 0.91 & 0.91 & 0.87 & 0.82 & 0.60 & 0.12 \\
\hline $\mathrm{C} / \mathrm{I}_{\mathrm{f}}: \mathrm{b}$ future GR premium & 0.83 & 0.86 & 0.81 & 0.79 & 0.65 & 0.37 \\
\hline \multicolumn{7}{|l|}{ Males, currently age 18 : } \\
\hline Future total income $\left(\mathrm{I}_{\mathrm{f}}\right)^{\mathrm{c}}$ & 14,265 & 38,628 & 86,015 & 138,367 & 198,924 & 258,629 \\
\hline Future age-rated premium ${ }^{\mathrm{d}}$ & 611 & 964 & 2,837 & 10,361 & 41,964 & 123,557 \\
\hline Future GR premium $^{\mathrm{d}}$ & 1,536 & 2,378 & 6,608 & 14,426 & 36,832 & 76,025 \\
\hline $\mathrm{C} / \mathrm{I}_{\mathrm{f}} \mathrm{:b}$ future age-rated premium & 0.96 & 0.98 & 0.97 & 0.93 & 0.79 & 0.52 \\
\hline $\mathrm{C} / \mathrm{I}_{\mathrm{f}}: \mathrm{b}$ future GR premium & 0.89 & 0.94 & 0.92 & 0.90 & 0.81 & 0.71 \\
\hline
\end{tabular}

Sources: 1996, 1997, 1998, and 1999 Medical Expenditure Panel Surveys; 2002 Current Population Survey.

a Total income (I) is for fulltime workers and is presented in 2003 dollars.

${ }^{\mathrm{b}}$ Consumption (C) is defined as total income minus the relevant health insurance premium.

${ }^{c}$ Future total income $\left(\mathrm{I}_{\mathrm{f}}\right)$ is for fulltime workers and is presented for the relevant future year, assuming annual three percent growth above current ages' levels.

${ }^{d}$ Future premiums assume projected growth rates presented in Heffler et al. [2003]. The annual growth rate for years 2004-2008 is projected to be 7.7 percent, the annual growth rate for years 2009-2012 is projected to be 6.9 percent, and we assume a 6.9 annual growth rate for years 2013 and beyond. 
Figure 1

Theoretical Guaranteed Renewable Premium Schedule Under a Set of Simple Assumptions

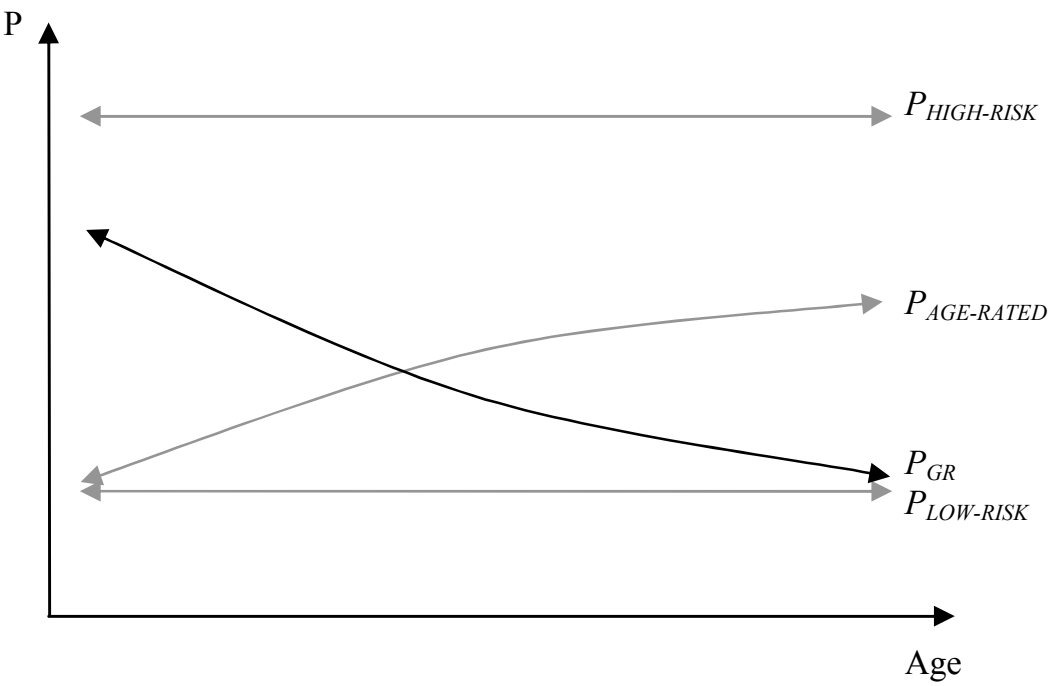

Note: The GR premium schedule shown here assumes that individuals are either low-risk or high-risk and that there is a constant per-period probability of low-risk individuals becoming (and staying) high-risk. By the final period of the model, one-half of the population is high-risk. 
Figure 2A

Female Hypothetical Risk-Rated Premium Schedules



Note: These estimates are given in 2003 dollars.

Figure 2B

\section{Male Hypothetical Risk-Rated Premium Schedules}



Note: These estimates are given in 2003 dollars. 


\section{Figure 3A \\ Female GR Premium Schedule}

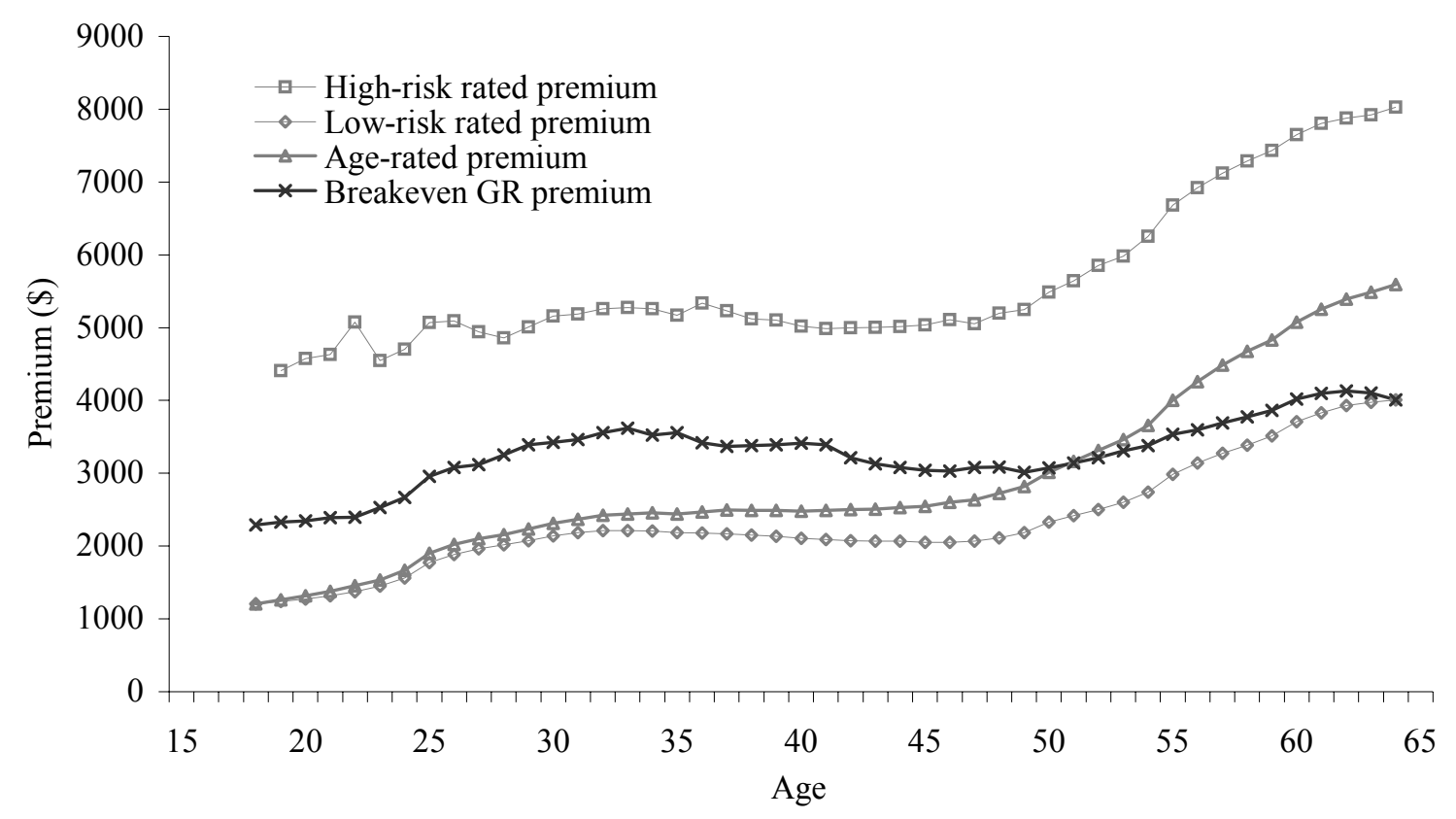

Note: These estimates are given in 2003 dollars.

Figure 3B

\section{Male GR Premium Schedule}

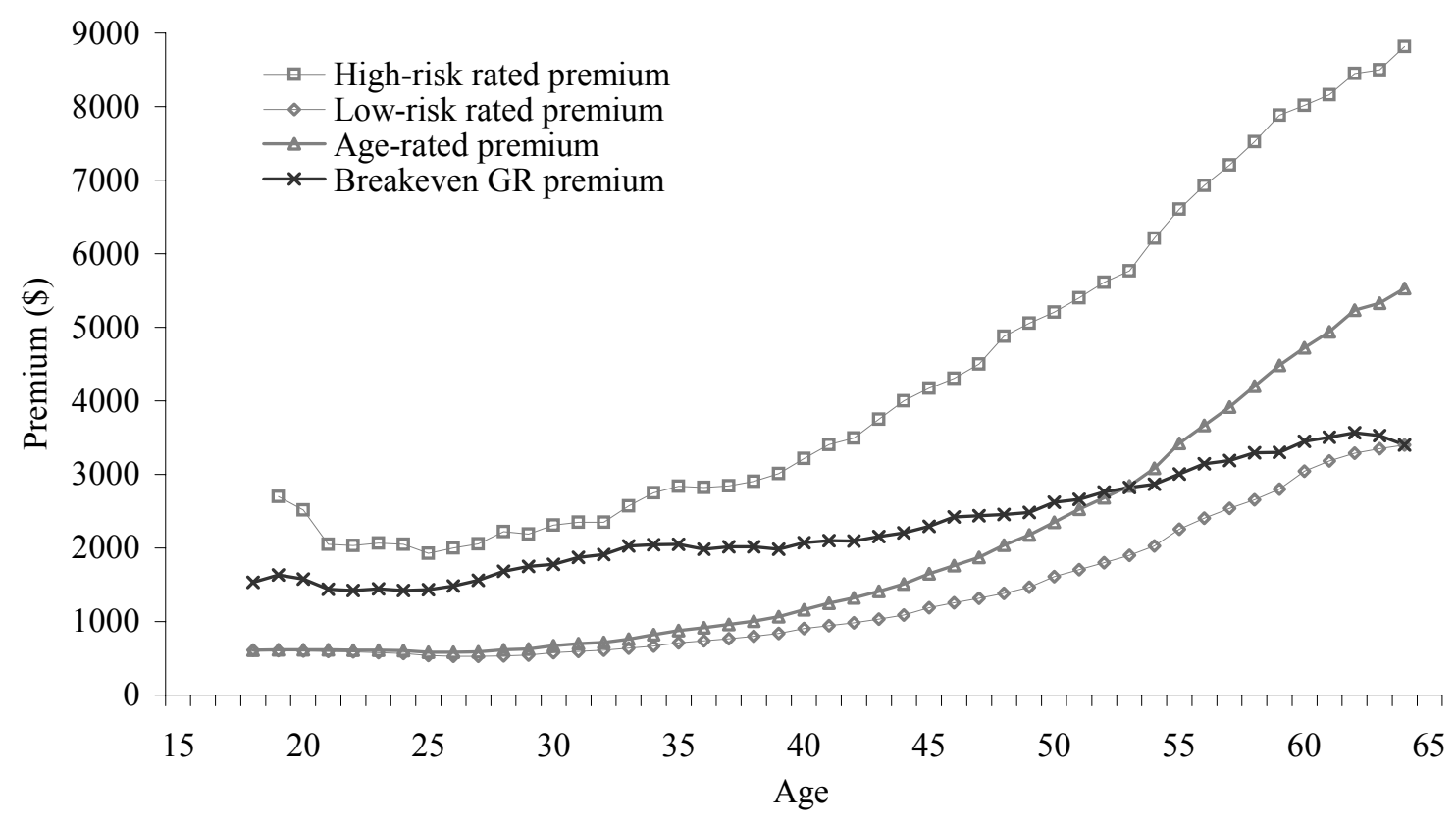

Note: These estimates are given in 2003 dollars. 
Figure 4A

Female Actual CTS Nongroup Premiums



Note: These values are given in 2003 dollars.

Figure 4B

Male Actual CTS Nongroup Premiums

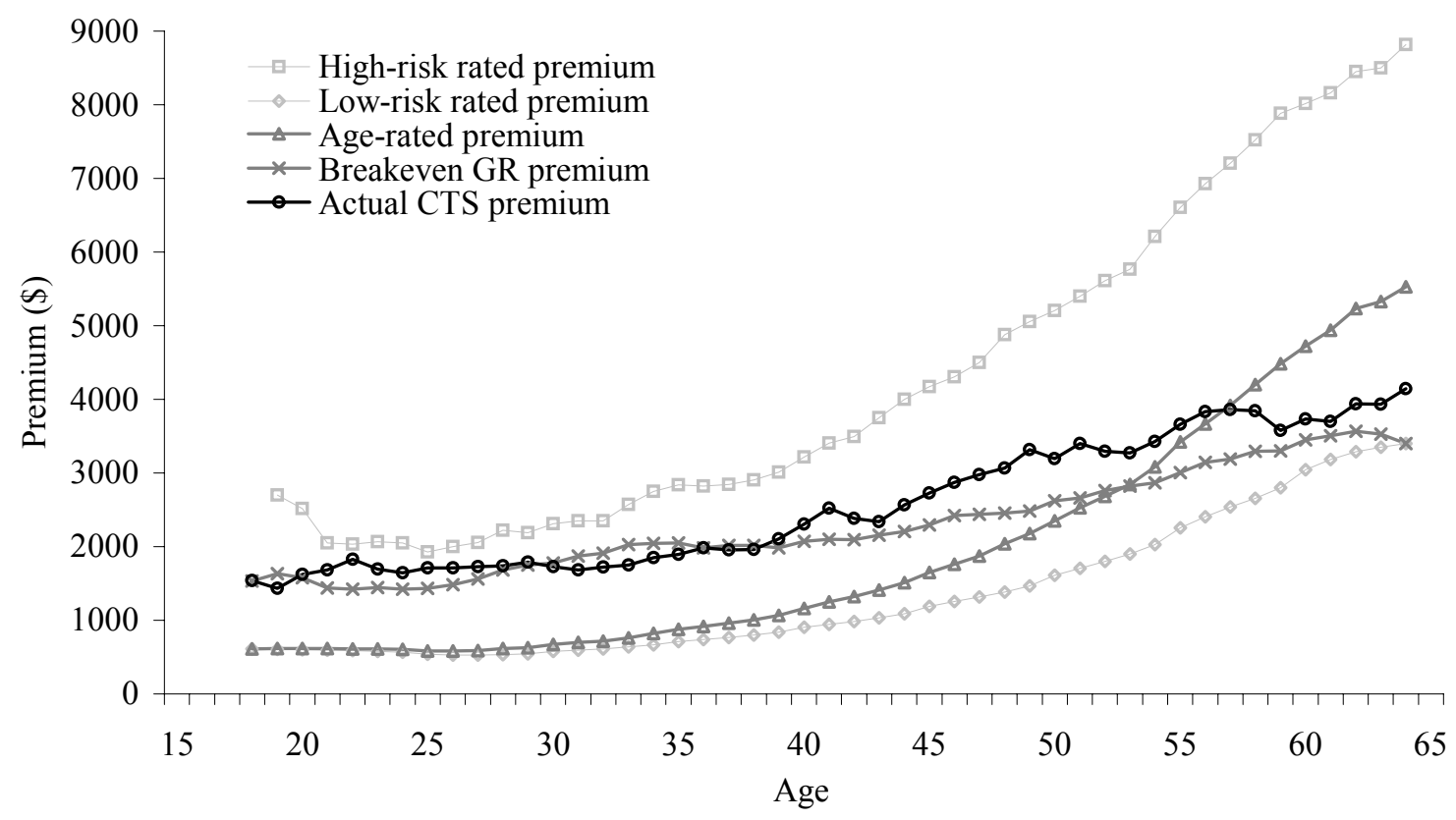

Note: These values are given in 2003 dollars. 


\section{Figure 5A}

\section{Alternative Female GR Premium Schedules}

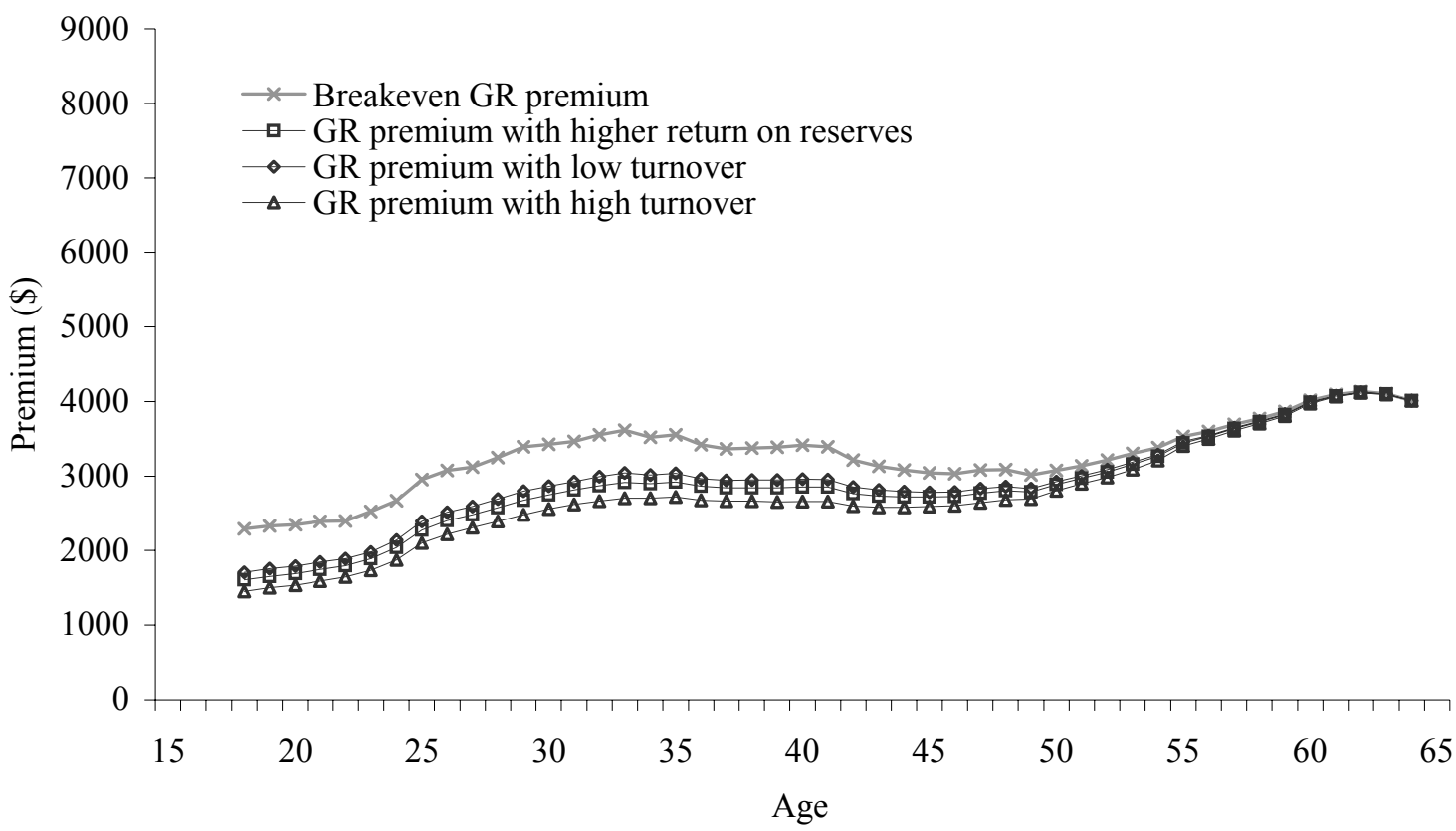

Note: These estimates are given in 2003 dollars.

Figure 5B

\section{Alternative Male GR Premium Schedules}

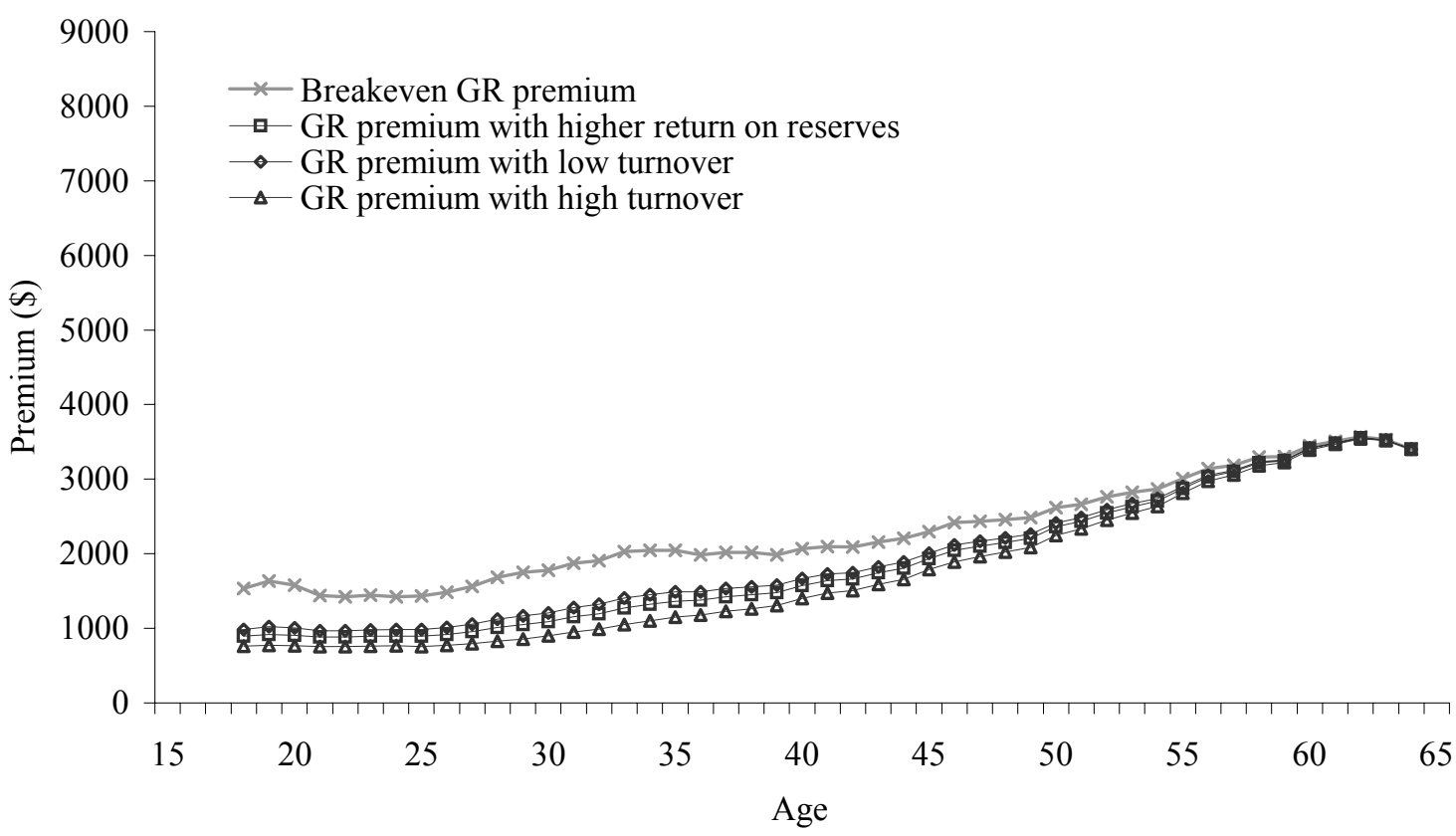

Note: These estimates are given in 2003 dollars. 
Figure 6A

Female Willingness-to-Pay for GR: Five Percent Discount Rate

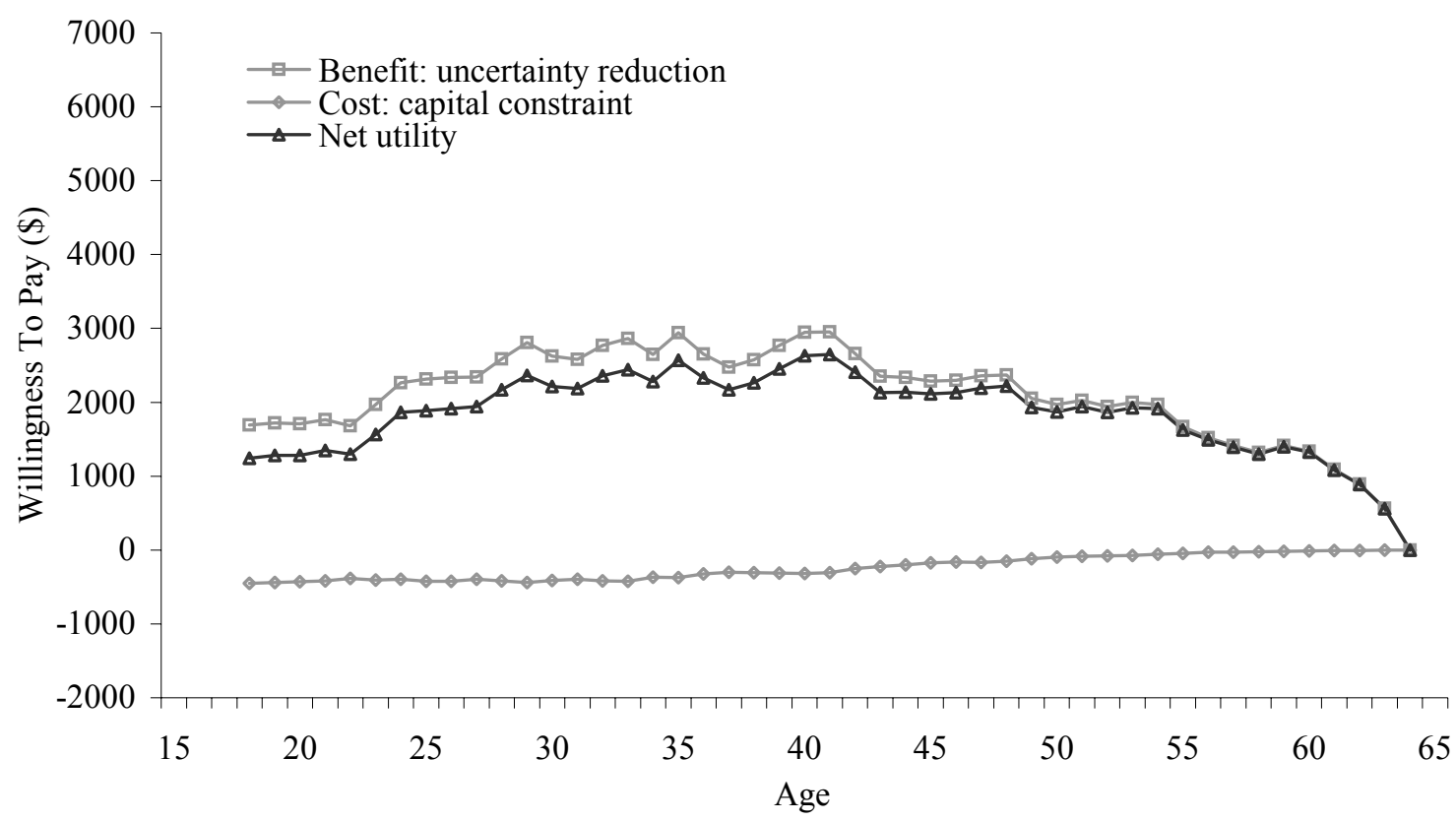

Note: The methodology for these estimates is provided in the text; values are given in 2003 dollars.

Figure 6B

Male Willingness-to-Pay for GR: Five Percent Discount Rate

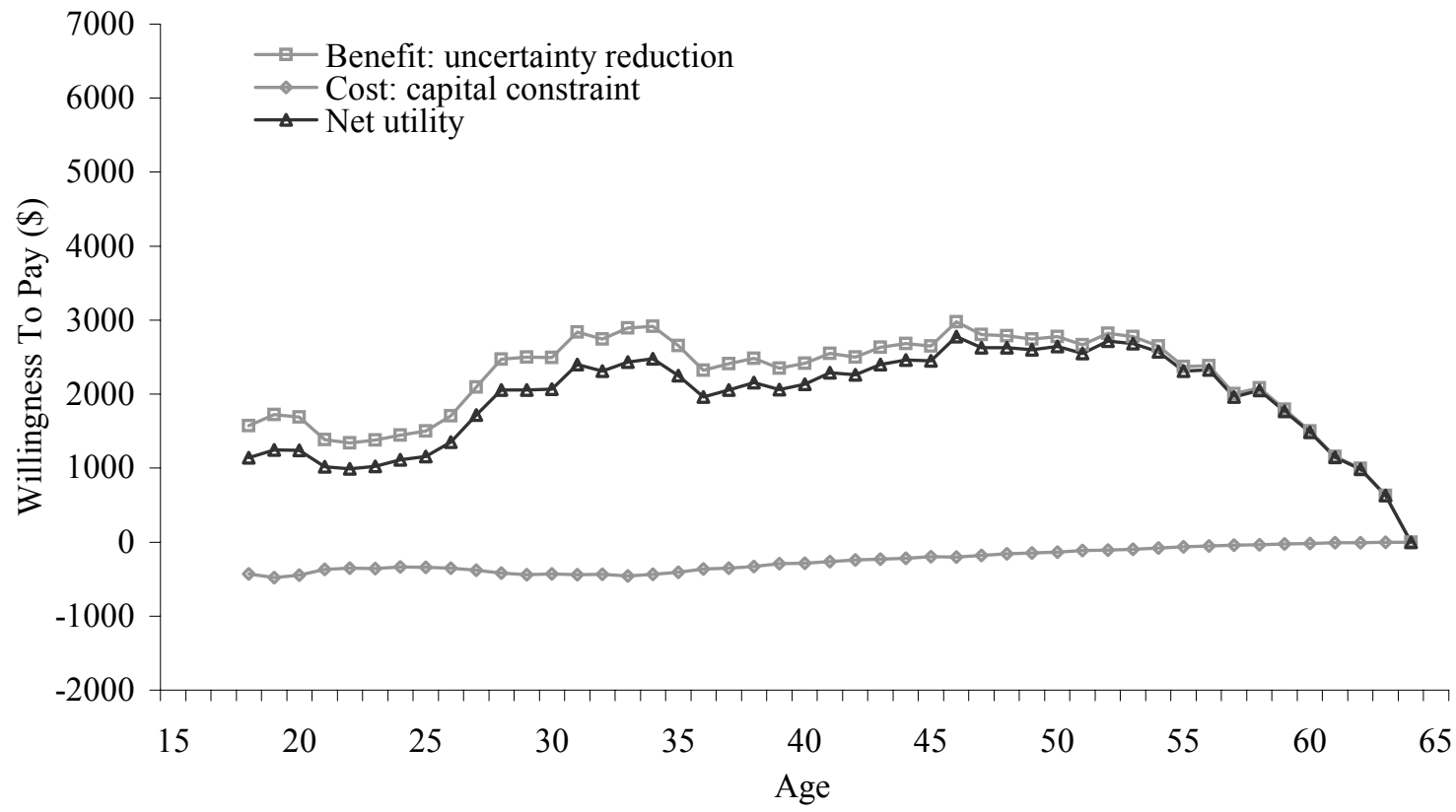

Note: The methodology for these estimates is provided in the text; values are given in 2003 dollars. 
Figure 7A

Female Willingness-to-Pay for GR: Ten Percent Discount Rate

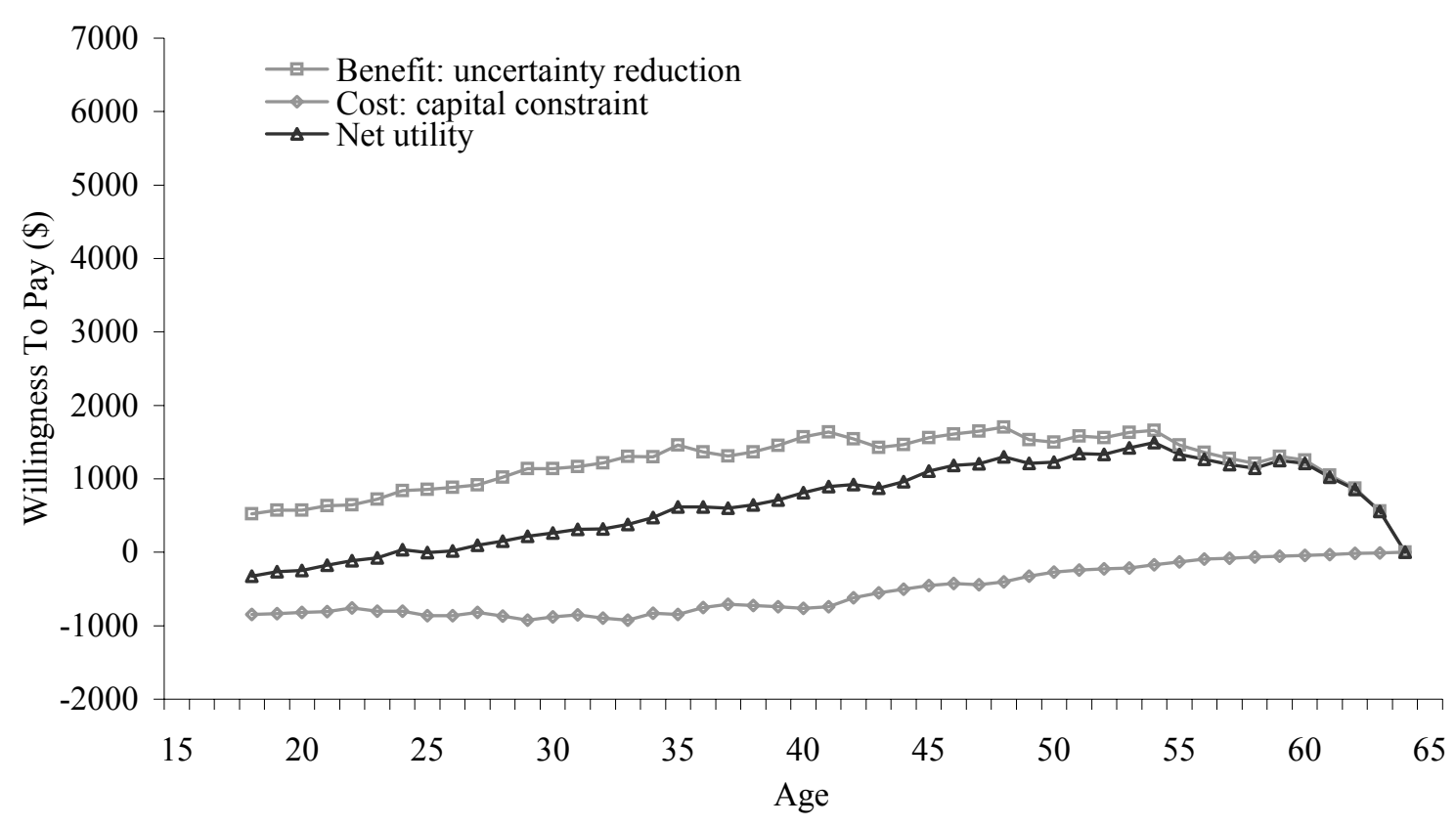

Note: The methodology for these estimates is provided in the text; values are given in 2003 dollars.

Figure 7B

Male Willingness-to-Pay for GR: Ten Percent Discount Rate

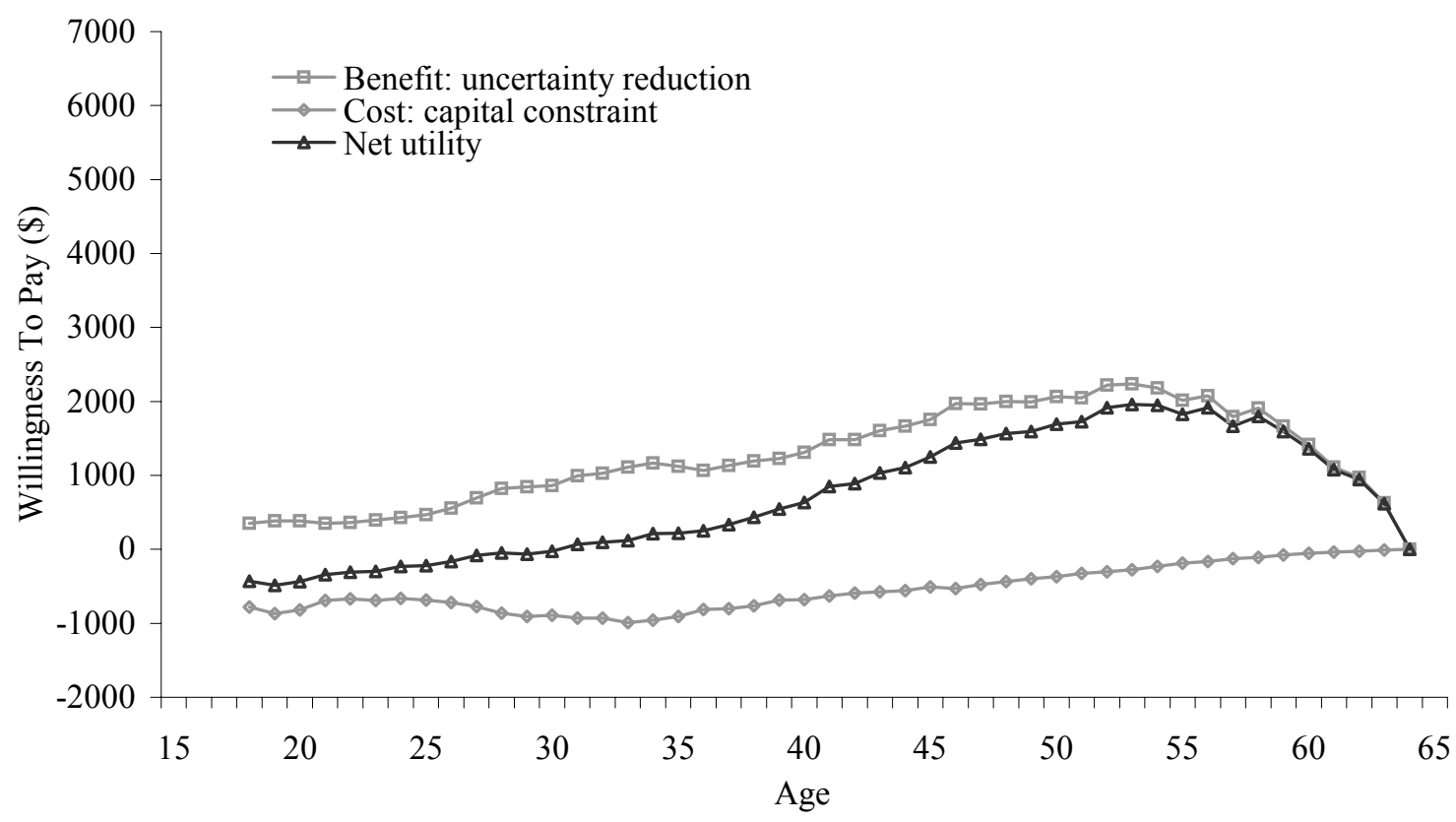

Note: The methodology for these estimates is provided in the text; values are given in 2003 dollars. 